\title{
Hsp90 co-chaperones, FKBP52 and Aha1, promote tau pathogenesis in aged wild-type mice
}

\author{
Marangelie Criado-Marrero ${ }^{1,2 \dagger}{ }^{1}$, Niat T. Gebru ${ }^{1,2 \dagger}{ }^{1}$, Danielle M. Blazier ${ }^{1,2}$, Lauren A. Gould ${ }^{1,2}$, Jeremy D. Baker ${ }^{1,2}$, \\ David Beaulieu-Abdelahad ${ }^{1,2}$ and Laura J. Blair ${ }^{1,2,3^{*}}$ (1)
}

\begin{abstract}
The microtubule associated protein tau is an intrinsically disordered phosphoprotein that accumulates under pathological conditions leading to formation of neurofibrillary tangles, a hallmark of Alzheimer's disease (AD). The mechanisms that initiate the accumulation of phospho-tau aggregates and filamentous deposits are largely unknown. In the past, our work and others' have shown that molecular chaperones play a crucial role in maintaining protein homeostasis and that imbalance in their levels or activity can drive tau pathogenesis. We have found two co-chaperones of the $90 \mathrm{kDa}$ heat shock protein (Hsp90), FK506-binding protein 52 (FKBP52) and the activator of Hsp90 ATPase homolog 1 (Aha1), promote tau aggregation in vitro and in the brains of tau transgenic mice. Based on this, we hypothesized that increased levels of these chaperones could promote tau misfolding and accumulation in the brains of aged wild-type mice. We tested this hypothesis by overexpressing Aha1, FKBP52, or mCherry (control) proteins in the hippocampus of 9-month-old wild-type mice. After 7 months of expression, mice were evaluated for cognitive and pathological changes. Our results show that FKBP52 overexpression impaired spatial reversal learning, while Aha1 overexpression impaired associative learning in aged wild-type mice. FKBP52 and Aha1 overexpression promoted phosphorylation of distinct AD-relevant tau species. Furthermore, FKBP52 activated gliosis and promoted neuronal loss leading to a reduction in hippocampal volume. Glial activation and phospho-tau accumulation were also detected in areas adjacent to the hippocampus, including the entorhinal cortex, suggesting that after initiation these pathologies can propagate through other brain regions. Overall, our findings suggest a role for chaperone imbalance in the initiation of tau accumulation in the aging brain.
\end{abstract}

Keywords: Tau, FKBP52, Aha1, Molecular chaperones, Alzheimer's disease, Neuroinflammation

\section{Introduction}

Alzheimer's disease (AD) is a progressive neurodegenerative disease and the most common cause of dementia in older adults [45]. The accumulation of tau, encoded by the $M A P T$

\footnotetext{
*Correspondence: laurablair@usf.edu

${ }^{\dagger}$ Marangelie Criado-Marrero and Niat T. Gebru have contributed equally to this work

${ }^{1}$ USF Health Byrd Alzheimer's Institute, University of South Florida, Tampa, FL 33613, USA

Full list of author information is available at the end of the article
}

gene, in the brains of $\mathrm{AD}$ patients is one of the pathological drivers of disease progression [86]. Tau is an abundant protein in the peripheral and central nervous systems that functions to stabilize neuronal microtubules [54, 65]. Under pathological conditions, tau disassociates from the microtubules, misfolds, becomes hyperphosphorylated, and forms aggregates. These conformational changes in tau are thought to contribute to disease progression and neurodegeneration in $\mathrm{AD}$ and other tauopathies [51, 91, 93].

As an effort to better understand tau-mediated pathological and neurobehavioral outcomes in $\mathrm{AD}$, many

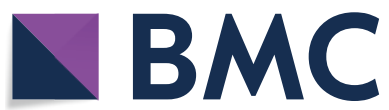

(c) The Author(s) 2021, corrected publication 2021. Open Access This article is licensed under a Creative Commons Attribution 4.0 International License, which permits use, sharing, adaptation, distribution and reproduction in any medium or format, as long as you give appropriate credit to the original author(s) and the source, provide a link to the Creative Commons licence, and indicate if changes were made. The images or other third party material in this article are included in the article's Creative Commons licence, unless indicated otherwise in a credit line to the material. If material is not included in the article's Creative Commons licence and your intended use is not permitted by statutory regulation or exceeds the permitted use, you will need to obtain permission directly from the copyright holder. To view a copy of this licence, visit http://creativecommons.org/licenses/by/4.0/. The Creative Commons Public Domain Dedication waiver (http://creativecommons.org/publicdomain/zero/1.0/) applies to the data made available in this article, unless otherwise stated in a credit line to the data. 
transgenic mouse lines have been created that show tau accumulation, some with cognitive deficits and neuronal loss, which recapitulate aspects of the tauopathic brain $[73,82,104]$. However, they also have limitations often including the need to use tau mutations and/or overexpression $[82,104]$, which are not found in the AD brain. Drift in the reliability of the line over time and between groups, and genetic disruptions that contribute to the neurodegenerative features have also been reported [35, $49,52]$. The contribution of aging, the strongest risk factor for tauopathies including AD [1], is not appropriately modeled in these mice. Mouse models have also been created that express human tau at endogenous levels $[3,43,44,81]$, which are useful for studying age-related aspects of tauopathy. While these models have some tau accumulation, they still do not capture the cascade of pathological events in the AD brain. Because of this many groups are now potentiating the pathology in these models by injecting pathological tau seeds $[21,71]$, which is informative at understanding the propagation of tau through the brain but does not allow us to understand which events initiate tau accumulation under normal physiological conditions.

As we age, our cells become less efficient at maintaining proper protein folding and disposal [56]. Cells employ highly conserved proteins known as molecular chaperones to maintain protein homeostasis [42, 55]. Molecular chaperones regulate protein synthesis, folding, trafficking, and assembly of multiprotein complexes to maintain a balanced protein quality control system [12]. They also facilitate degradation of terminally modified or misfolded proteins, an essential role within the proteostasis network $[68,91]$. Major imbalances in the chaperone system have been reported in the aged brain, where $32 \%$ of chaperones are downregulated and almost $20 \%$ of chaperones are upregulated [14]. Those that decrease are predominantly ATP-dependent chaperones required for protein folding whereas those that increase are more commonly ATP-independent chaperones and co-chaperones [14]. Further changes in molecular chaperone expression have also been shown in the AD brain $[15,33,58]$. These ageand $\mathrm{AD}$-associated changes in molecular chaperones may be early events that contribute to the cascade of pathologies associated with AD. In fact, work from our group and others has shown that high expression of certain molecular chaperones can drive the aggregation of tau [11, $17,23,36,53,90]$. A well-studied and highly conserved chaperone is the $90 \mathrm{kDa}$ heat shock protein (Hsp90) that maintains cellular homeostasis $[63,80]$. However, under pathological conditions, Hsp90 can promote the accumulation of tau [11, 23, 101]. Specific actions on tau protein will depend on the association of Hsp90 with many other chaperones forming a heterocomplex $[11,18,19,74,90]$.
In this study, we investigated the effects of two Hsp90 co-chaperones on tau in the aged brain: the activator of $90 \mathrm{kDa}$ heat shock protein ATPase homolog 1 (Aha1) and the $52 \mathrm{kDa}$ FK506-binding protein (FKBP52). Recently, we have found that these proteins cause increased tau accumulation in the brains of tau transgenic mice [19, 90].

Aha1 is a cytosolic Hsp90 co-chaperone that promotes Hsp90 ATPase activity [62]. In the past, we have shown that the overexpression of Aha1 in the hippocampus of tau transgenic mice increased oligomeric and insoluble tau, which was complemented by neuronal loss and cognitive impairments [91]. There was also a modest increase, although not significant, in soluble tau levels in the hippocampus of 5-month-old wild-type mice after 3 months of Aha1 overexpression. In postmortem AD brains, Aha1 colocalized with pathogenic tau and correlated with disease progression [90]. In addition to tau, Aha1 stabilizes other Hsp90 clients including mutant cystic fibrosis transmembrane conductance regulator, CFTR, which causes cystic fibrosis $[59,100]$, and mutant melanocortin-4 receptor, another misfolded transmembrane protein [67]. Aha1 may also have a role in RNA processing and DNA repair [96].

FKBP52 is an Hsp90 co-chaperone highly expressed in neurons and a regulator of steroid hormone complexes $[76,103]$. Roles for FKBP52 in regulation of nuclear trafficking of multiprotein complexes-progesterone, glucocorticoid, and androgen receptors have been described [92]. FKBP52 can regulate microtubule assembly by directly binding to tau, preferentially in its hyperphosphorylated form [18]. FKBP52 promotes the aggregation of various tau species, including wild-type and P301L recombinant tau, leading to the formation of tau oligomers and fibrils $[18,37]$. The effect of FKBP52, but not Aha1, on tau aggregation is independent of Hsp90 and ATP $[18,19,36,71]$. In a recent study, we found that FKBP52 overexpression in the hippocampus of the rTg4510 tau transgenic mouse promotes spatial memory impairments and neuronal loss [19]. Different from Aha1, FKBP52 was found to be colocalized with normal but not pathological tau in the frontal cortex of human AD brains [38]. Interestingly, the same study revealed that FKBP52 levels were lower in AD brains when compared to control subjects. However, the cause and consequences of this decrease in FKBP52 levels are still not clearly understood. Aha1 and FKBP52 were associated with reduced cognitive trajectory, in a recent study investigating the association of proteins with the stability of cognition through aging [102]. Together, this led us to hypothesize that imbalance in these chaperones may occur at different timings before or during disease progression and that these chaperones may be useful to model if chaperone 
dysregulation is sufficient to trigger tau misfolding in the aging brain.

Aha1 and FKBP52 can bind to Hsp90 simultaneously, but they compete with other Hsp90 co-chaperones [96]. The composition of Hsp90 heterocomplexes affects client maturation and activity [10]. In particular, the activity of steroid hormone complexes, like the glucocorticoid (GR) and mineralocorticoid (MR) receptors, are directly modulated by the binding of these co-chaperones to Hsp90. Aha1 competes with GR to bind Hsp90 [66]. Hsp90 inhibition reduces GR and MR activity [6], but HAM-1, an inhibitor of Hsp90/Aha1 client processing, did not alter GR activity, while MR activity was reduced [95]. This highlights that Aha1 is important for the maturation of MR, but not GR. In contrast, FKBP52 has been shown to increase GR, but not MR, activity [27, 34]. However, FKBP52 is important for the nuclear localization of MR, which precedes its activation [34]. Given their overlapping effects on tau accumulation and differing effects steroid hormone complexes, Aha1 and FKBP52 are prime candidates to investigate how chaperone imbalance may contribute to declined proteostasis during aging.

The present study evaluated whether upregulation of Aha1 or FKBP52 could initiate a pathological cascade to cause tau accumulation in the brains of aged wildtype mice. In addition to tau, we examined the effects on neuroinflammation and neurodegeneration in the hippocampus and its adjacent cortical areas. Behavioral tasks of learning and memory were also performed to test cognitive impairments. We found that high levels of these chaperones were enough to promote pathological and phenotypic consequences. Our findings are highly relevant to understand how protein dysregulation during normal aging may promote the molecular and behavioral phenotype seen in tauopathies.

\section{Materials and methods Virus production}

Aha1, FKBP52, and mCherry were subcloned into pTR12.1-MCS vector containing a short hybrid CMV/ chicken $\beta$-actin promoter [20]. All plasmids were confirmed by sequencing. Aha1-pTR12.1, FKBP52-pTR12.1 or mCherry-pTR12.1 were co-transfected with helper plasmids pF $\Delta 6$ and pAAV9 into HEK293T using polyethyleneimine to generate adeno-associated virus serotype 9 (AAV9) particles. After $72 \mathrm{~h}$, the recombinant virus was harvested by three cycles of freeze-thaw between dry-ice and $37{ }^{\circ} \mathrm{C}$ water bath. The crude lysate was clarified by centrifugation at $4000 \times g$ for $20 \mathrm{~min}$ and purified using four iodixanol gradients. After concentration to $200 \mu \mathrm{L}$, a SYBR-green-based real time PCR was used to determine the viral titer in genomes/mL.

\section{Mouse colony and viral injections}

Wild-type mice (129S6 X FVB/N background) were obtained from our colony at the University of South Florida vivarium. They were housed up to five per cage, maintained under standard conditions with a 12-h light/ dark cycle, and had free access to food and water. Animal experiments were carried out accordingly with the $\mathrm{NIH}$ Guide for the Care and Use of Laboratory Animals and approved by the University of South Florida Institutional Animal Care and Use Committee (IACUC). At 9 months of age, mice $(\mathrm{N}=6$ for each condition) were injected with AAV9 expressing Aha1, FKBP52, or mCherry (control) using a robotic stereotaxic surgery unit (Neurostar GmbH, Tubingen, Germany). A total of $2 \mu \mathrm{L}$ of $1 \times 10^{12}$ genomes $/ \mathrm{mL}$ viral particles was delivered into each injection site using a high precision syringe (Hamilton 801 RN, HT7642-01, College Park, Georgia) with convection enhanced delivery [16] at the following coordinates: hippocampi $(X= \pm 3.6, Y=-3.5$, and $Z=+2.68)$ and cortex $(\mathrm{X}= \pm 2.2, \mathrm{Y}=+1.7$, and $\mathrm{Z}=+3.0)$. After 7 months of expression, brain tissues were harvested from 16-monthold mice following transcardial perfusion using $0.9 \%$ saline solution.

\section{Immunohistochemistry}

Free-floating tissue was stained as previously described $[11,22]$. Briefly, tissue sections were incubated in PBS supplemented with $10 \% \mathrm{MeOH}$ and $3 \% \mathrm{H}_{2} \mathrm{O}_{2}$ to block endogenous peroxidases. Following PBS washes, tissue was permeabilized by $0.2 \%$ Triton-X-100 with $1.83 \%$ lysine and $4 \%$ goat serum in PBS for $30 \mathrm{~min}$. Tissue was incubated overnight at room temperature using the following primary antibodies: Total tau (Dako; 1:100,000, Aligent A002401, Santa Clara, CA, USA), FKBP52 (1:1000, R\&D Systems MAB4095, Minneapolis, MN, USA), Aha1 (1:100, Stressmarq Biosciences SMC172D, Victoria, British Columbia, Canada), pT231 Tau (1:300, Anaspec AS-55313, Fremont, CA, USA), AT8-biotin (S202/T205; 1:5000, Thermo Fisher ENMN1020B, Waltham, MA, USA), pS396 Tau (1:5000, Anaspec AS-54977, Fremont, CA, USA), T22 (1:15,000, Millipore ABN454, Burlington, MA, USA), GFAP (1:10,000, Millipore MAB360, Burlington, MA, USA), and IBA1 (1:10,000, WAKO 019-19741, Chuo-Ku, Tokyo, Japan). After washes, sections were incubated for two hours with the corresponding secondary antibodies (Southern Biotech, Birmingham, AL, USA). A Vectastain ABC kit (Vector Laboratories, PK-4000, San Francisco, CA, USA) was used to increase visibility. This was followed by washes, incubation with $0.05 \%$ diaminobenzidine plus $0.5 \%$ nickel sulfate hexahydrate in TBS and development with $0.03 \%$ $\mathrm{H}_{2} \mathrm{O}_{2}$. Following washes, tissue sections were mounted 
and allowed to dry overnight before dehydration in alcohol gradients. Slides were cleared by Histoclear then coverslipped with DPX mountant. Tissue sections were mounted on glass slides, dried overnight, and coverslipped using Prolong Gold Antifade Reagent (Invitrogen P36934) for mCherry detection.

\section{Gallyas silver staining}

Tissue slices were mounted on glass slides and dried overnight. Sections were washed twice with distilled water and incubated in 5\% periodic acid for five minutes. After two five-minute washes with distilled water, sections were incubated in alkaline silver iodide solution (1 M sodium hydroxide, 0.6 M potassium iodide, 0.053\% silver nitrate) for one minute. Sections were then washed with $0.5 \%$ acetic acid for $10 \mathrm{~min}$. Staining was developed by combining solutions A (5\% sodium carbonate), B (0.024 M ammonium nitrate, $0.012 \mathrm{M}$ silver nitrate, $0.003 \mathrm{M}$ tungstosilicic acid), and $\mathrm{C}(0.024 \mathrm{M}$ ammonium nitrate, $0.012 \mathrm{M}$ silver nitrate, $0.003 \mathrm{M}$ tungstosilicic acid, $0.25 \%$ formaldehyde) in a 10:3:7 ratio. Adding B first to A and then adding $C$. Slides were submerged in this solution with constant mixing for $10 \mathrm{~min}$. The slides were then washed in $0.5 \%$ acetic acid for three min, then distilled water for five min. Slides were then incubated in $0.1 \%$ gold chloride for $5 \mathrm{~min}$ and again rinsed with distilled water. Slides were incubated in $0.1 \%$ sodium thiosulphate solution for $5 \mathrm{~min}$ and washed with tap water. Finally, they were rapidly dehydrated using EtOH gradients and coverslipped with xylenes.

\section{Stereology and high magnification images}

Tissue was stained with biotinylated NeuN (1:100, EMD Millipore MAB377B) as described above, but without $0.5 \%$ nickel sulfate hexahydrate and TBS. Tissues were mounted and before coverslipping they were counterstained with $0.05 \%$ cresyl violet (Nissl) to quantify neurons. Only those positive for both NeuN and Nissl stains in the Cornu ammonis 1 (CA1) region of the hippocampus were counted. A stereology workstation consisting of a modified Leica DM4000B light microscope with a Prior motorized stage was used to outline the area using distinct landmarks in the brain at $4 \times$ magnification $[2,69]$. Neurons in this region were counted using randomly designated areas in the computer-generated grid using a $100 \times$ oil immersion objective. Neurons were counted when they were located within the three-dimensional dissectors or touching the inclusion lines, and the top $1 \mu \mathrm{m}$ and bottom $1 \mu \mathrm{m}$ of tissue were excluded. High magnification images of tau staining in the hippocampus were also taken using the high power (100x, NA 1.3) oil immersion objective on this microscope.

\section{Image analysis and statistics}

Zeiss Axio Scan.Z1 (ZEISS Microscopy, Munich, Germany) was used to image all tissue slides. Pixelbased bright-field image analysis software, NearCYTE (http://nearcyte.org), was used to outline a region of interest within the tissue. Threshold was adjusted to select only stain positive cells. Parametric segmentation method was used to create a file for each stain and applied using a batch processing option to enable the quantification of percent area ratio of positive cells within the selected regions of interest for each slide. Mean area ratio was used for each group for graphical representation. Significant outliers were detected using GraphPad Prism 8.0 (GraphPad Software, San Diego, CA, USA).

\section{Open field}

Prior to each behavioral test, mice were acclimated to the testing room for a minimum of $30 \mathrm{~min}$. Then, individual mice were placed in the center of the box and allowed to explore for a period of $10 \mathrm{~min}$ while video recorded. Time spent in the center and corners as well the total distance travelled by each mouse was monitored and analyzed using the ANY-maze (Stoelting, www.anymaze.com) video tracking software operated by a blinded observer.

\section{Radial-arm water maze (RAWM)}

The RAWM task was used to test for spatial learning and memory deficits in these mice. A black round swimming pool containing 6 radial metal arms was filled with water. A submerged platform ( $1 \mathrm{~cm}$ below surface) was placed in the goal arm. During the first day, each animal was permitted swim for up to $60 \mathrm{~s}$ per trial to locate the platform (length of each trial). A visible and hidden platform was alternated between trials. During the second day, mice were trained leaving a hidden platform throughout the trials. The last day of training, the platform was moved to the counter-goal arm (new goal). Each day consisted in 12 trials (4 block sessions, 3 trials each). A blind observer manually scored the number of errors in each trial. An error was defined as entry into incorrect arm or no arm entry within the first $15 \mathrm{~s}$. If an animal failed to locate the platform in the allow time, they were manually led to the platform. Once mice reached platform, they were allowed to observe the spatial cues for one minute.

\section{Fear conditioning}

Associated learning and memory is mainly regulated by hippocampal projections. Thus, deficits in associative learning and contextual memory were evaluated by training the mice to associate a conditioned stimulus (70-dB tone) presented for $30 \mathrm{~s}$ that co-terminated with 
an unconditioned stimulus ( $2 \mathrm{~s}, 0.5 \mathrm{~mA}$ foot shock). Twenty-four hours later, mice were placed into the same chamber as the first day and monitored for $3 \mathrm{~min}$ without tone or shock exposure (Context). On the next day, mice were placed back into a novel context for three minutes and exposed to a 70- $\mathrm{dB}$ tone for three minutes without a shock (Cued). Freezing (lack of movement) was evaluated every $10 \mathrm{~s}$ by a blind observer to the experiment. Averages of percent freezing by min are shown.

\section{Statistical analysis}

Statistical analysis for open field, immunostained tissues, and stereology was performed using one-way analysis of variance (ANOVA). RAWM and fear tests were analyzed by repeated measures two-way ANOVA. When significant, the analysis was followed by Tukey's post-hoc test using GraphPad Prism 8. Data normal distribution was confirmed by Shapiro-Wilk test. Spearman rank correlations were calculated to examine associations between tau-related proteins, neuronal count, and neuroinflammatory cell markers. Significant difference was considered when p values where less than $0.05\left({ }^{*}\right), 0.01\left({ }^{* * *}\right)$ and $0.0011^{(* * *)}$ as described in figure legends. Data is presented as the standard error of the mean $( \pm$ SEM).

\section{Results}

High FKBP52 levels impair spatial reversal learning, while overexpression of Aha1 impairs associative learning in aged wild-type mice

This study takes advantage of the use of adeno-associated viral vector to overexpress Aha1, FKBP52 or mCherry (control) in an aged wild-type mouse. AAV serotype 9, used in this study, has been reported to target expression mainly in neurons and astrocytes with high transduction efficiency [26, 31]. Using AAV9 also overcomes some of the limitations offered by transgenic mice (genetic drift and disruptions) [52]. To determine if chaperone imbalance could initiate tau pathogenesis in the aged brain, we bilaterally injected 9-month-old wild-type mice with AAV9 to express mCherry, Aha1, or FKBP52 $(\mathrm{N}=6$ for each group) in the hippocampus (Fig. 1a). The use of AAV9 provided several advantages including a long-term stable expression of these chaperones without causing a chronic immune response in the brain at specifically selected timepoints [83]. In these mice, the virus was expressed for 7 months before exposing them to behavioral testing and, subsequently, collecting brain tissue at 16 months of age. Confirmation of viral overexpression by tissue quantification of mCherry, Aha1, and FKBP52 in the hippocampus is shown in Fig. 1b. Since neuropsychiatric symptoms like anxiety are common in early stage of $\mathrm{AD}$ [28], we first investigated whether our treatments increased anxiety-like behavior, while also assessing general motor ability to rule out confounding factors in our behavioral testing [88]. Overexpression of Aha1 or FKBP52 did not significantly affect mobility (measured by total distance) (Fig. 2a) or anxiety levels (measured by total time spent in the center) (Fig. 2b), although there was a trend toward an increase in anxiety-like behavior in Aha1 expressing mice when compared to control $(\# p=0.07)$. Because the accumulation of tau is critically linked with the progression of dementia in $\mathrm{AD}$ patients $[4,13,32,70,72,73,77,79,89]$, we assessed whether high levels of Aha1 or FKBP52 affect associative fear and spatial learning in aged wild-type mice. In the fear conditioning test, Aha1 injected mice spent significantly less time freezing during the last minute of the training day as compared to mCherry mice (Fig. 2c), suggesting that associative learning was impacted, but this did not result in contextual or cued memory deficits in the subsequent days. In the radial-arm water maze (RAWM) task no differences in learning and memory were identified during training (day 1) and testing (day 2) (Fig. 2d). On day 3, when increasing difficulty and testing for flexibility in learning a new spatial goal (reversal testing), FKBP52 injected animals made significantly more errors than control injected mice in locating the escape platform, indicating less flexibility and an impairment in reversal spatial learning. These results suggest that disrupted levels of FKBP52 and Aha1 alter cognitive ability of aged wild-type mice.

\section{High levels of Aha1 or FKBP52 increase unique tau phosphosites without affecting oligomeric tau in wild-type mice}

Since we know these chaperones promote the aggregation of human tau $[19,90]$ and strong correlations between cognitive impairments and tau pathology have been reported in multiple studies [7, 72, 78, 87], we next determined if these chaperones promoted the accumulation of murine tau. We measured levels of total tau as well as phospho-tau species in the hippocampus of these mice. Total tau was significantly increased by Aha1 (Fig. 3a, b) as well the levels of pT231 tau (Fig. 3c, d). Conversely, high levels of FKBP52 promoted AT8 (pS202/ T205) (Fig. 3e, f) and pS396 (Fig. 3g, h) tau phospho-species compared to mCherry injected mice. Oligomeric tau (T22) was not changed by high levels of these chaperones (Fig. 3i, j). Although no true tau tangles were observed, diffuse argyrophilic signal was significantly increased in the FKBP52 injected mice (Fig. 3k, l). Additional insets of $\mathrm{CA} 1, \mathrm{CA} 3$ and dentate gyrus representing these tissue analyses can be found in Additional file 1: Fig. S1 a-f.

To gain a better understanding of the pattern of tau accumulation and how this relates to pathology in the tauopathic brain, we captured high magnification 
a

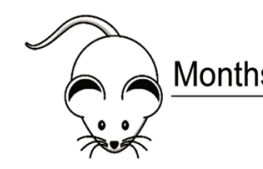

wild-type mice $129 \mathrm{~S} 6 \times \mathrm{FVB} / \mathrm{N}$

b

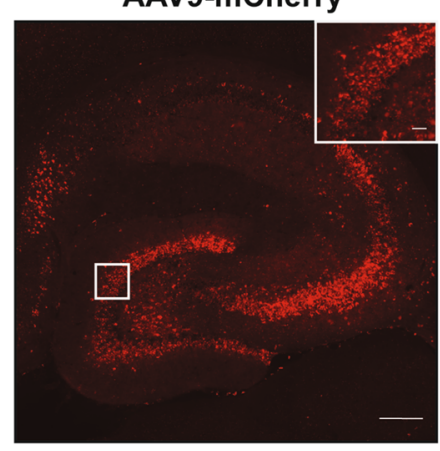

mCherry

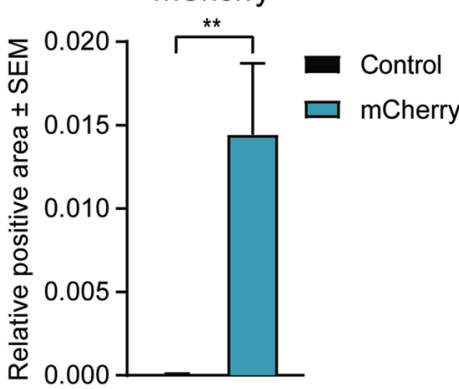

AAV9 intracranial injection (mCherry, Aha1, FKBP52)

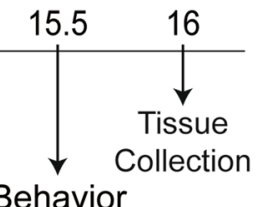

Behavior
AAV9-Aha1

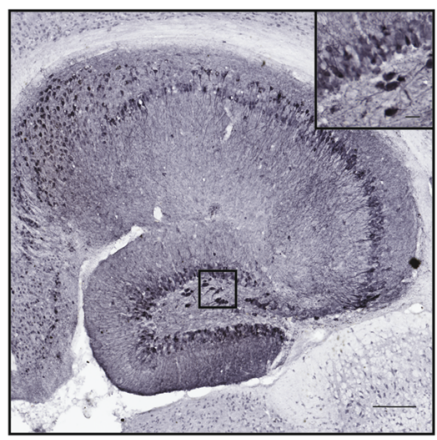

Aha1

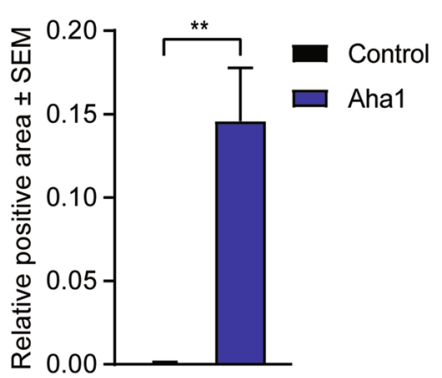

AAV9-FKBP52

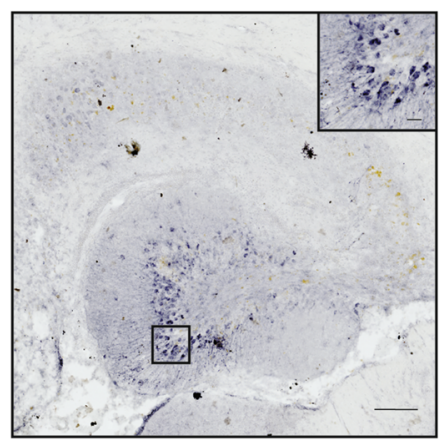

FKBP52

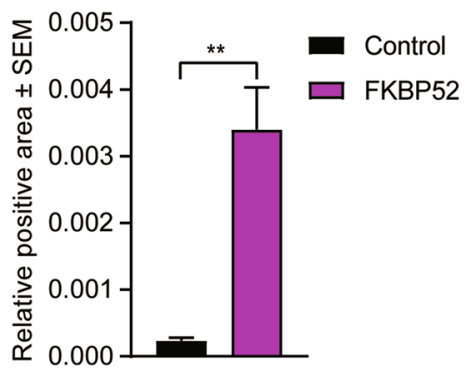

Fig. 1 AAV9 injection timeline and expression validation. (a) Timeline of bilateral hippocampal injections with AAV9-mCherry (control), AAV9-Aha1, or AAV9-FKBP52. At 15.5 months of age, mice were exposed to cognitive behavioral testing followed by brain collection for immunohistochemistry analysis. $N=6 / A A V$. (b) Representative images and quantification of viral expression after 7 months of injection in hippocampal sections from wild-type mice. Relative intensity was analyzed by Student's unpaired t-test comparing outside (control) and inside areas of injection. Statistical significance is indicated by ${ }^{* *} p<0.01$. Results are represented as standard error of the mean ( \pm SEM). Scale bar represents $100 \mu \mathrm{m}$; inset scale represents $10 \mu \mathrm{m}$. AAV9, adeno-associated virus serotype 9

images from the hippocampus of these mice specifically in the group that showed the most accumulation of tau (Fig. 3a-1). Tau depositions in AAV9-Aha1 neurons were highly concentrated in the perinuclear space as well as some axonal distribution (Fig. 4a). The neuronal population stained for pT231 (AAV9-Aha1 tissue) and AT8 (AAV9-FKBP52 tissue) tau also showed perinuclear and axonal pre-tangle accumulation but was more heterogeneous (Fig. 4b, c). Particularly, AT8-positive cells showed a mixture of diffused and granular immunoreactivity (Fig. 4c). The presence of these mixed features was also evident in the smaller population of pS396-positive neurons (AAV9-FKBP52 tissue; Fig. 4d). The minimal T22-reactivity that could be detected was found to be perinuclear in a randomly selected tissue section from an AAV9-Aha1 injected mouse (Fig. 4e). We also noted the presence of argyrophilic-like grains in the silver immunoreactive neurons in high FKBP52 expressing animals (Fig. 4f). Overall, identification of these key morphological features in the pre-tangle stage provide valuable information on how these chaperones may participate in the evolution of tangle formation.

\section{Overexpression of FKBP52, but not Aha1, promotes gliosis} and neuronal loss in aged mice

In addition to tau accumulation, elevated markers of gliosis are commonly detected in the brains of aged individuals and further elevated in $\mathrm{AD}[9,50,54,84]$. Here, we investigated whether Aha1 or FKBP52 overexpression affected gliosis through the activation of the two main glial cells: astrocytes and microglia. Hippocampal tissues overexpressing mCherry, Aha1, or FKBP52 were stained 


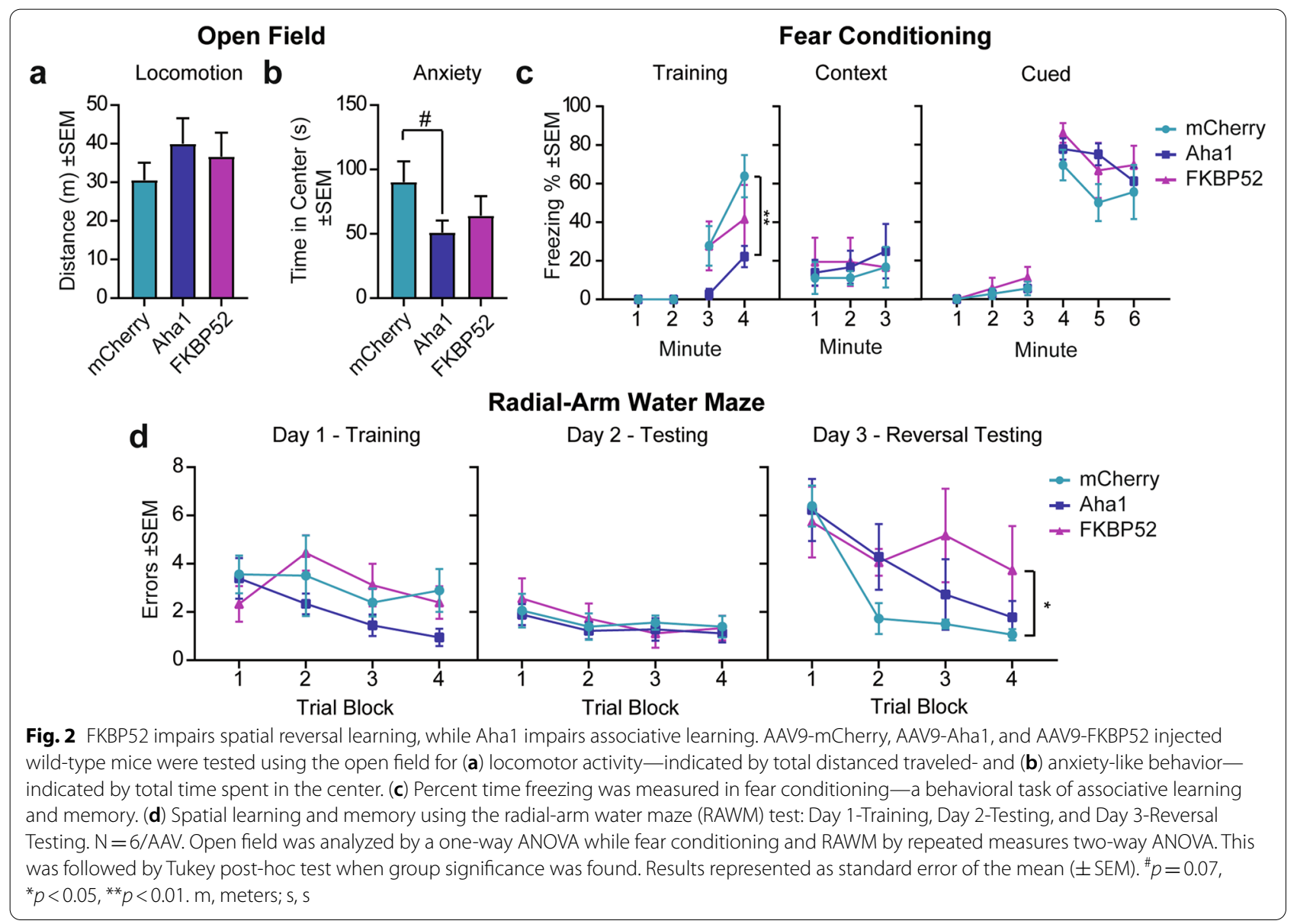

for GFAP (glial filially acidic protein, astrocytic marker) and IBA1 (ionized calcium binding adaptor molecule 1 , microglia marker). Glial cells remained relatively unaffected by Aha1 overexpression, however, FKBP52 significantly upregulated GFAP (Fig. 5a, b) and IBA1 (Fig. 5c, d) levels in the hippocampus, which implies a role for FKBP52 in promoting neuroinflammation in the aged brain, either dependently or independently on tau.

The exaggerated activation of glial cells as well as the cognitive deficits driven by FKBP52 denoted a possible detrimental effect on hippocampal neuron health. Using unbiased stereology, we examined the NeuN/cresyl violet-positive neuronal population in the hippocampal CA1 region (Fig. 6a). A significant neuronal loss (Fig. 6b) and reduced hippocampal volume (Fig. 6c) was observed in the FKBP52 injected animals. Neuronal number and tissue volume was not affected by Ahal overexpression. Using these data, we performed a correlation analysis to understand the association between tau accumulation, glial activation, and neuronal density. T22 was excluded in this assessment because its expression was not affected by Aha1 or FKBP52 (Fig. 3). In general, the nonparametric Spearman rank correlation analysis shows a highly significant association of neuroglial cells with high levels of FKBP52 (Fig. 7). There were strong positive correlations between AT8 phospho-tau and Gallyas silver staining with FKBP52. This was different from mCherry and Aha1 animals where only weak associations were found with IBA1 and AT8 and pS396 phospho-tau species. These data indicate that FKBP52 may be a potential driver of unique pathological events, like AT8 tau accumulation and activation of neuroglial cells, which may evoke a negative downstream effect on neuronal health in the hippocampus.

\section{FKBP52 triggers the accumulation of AT8 tau and markers} of neurogliosis in hippocampal adjacent cortices

In addition to the hippocampus, cortical areas play a key role in cognition and are vulnerable to tau pathology and neurodegeneration [24]. Here, we examined the presence of astrocyte and microglial markers in areas adjacent to the hippocampus. Aha1 or FKBP52 did not affect total tau levels in the ectorhinal cortex, perirhinal cortex, entorhinal cortex or the subiculum (Fig. 8a). Because FKBP52 induced 


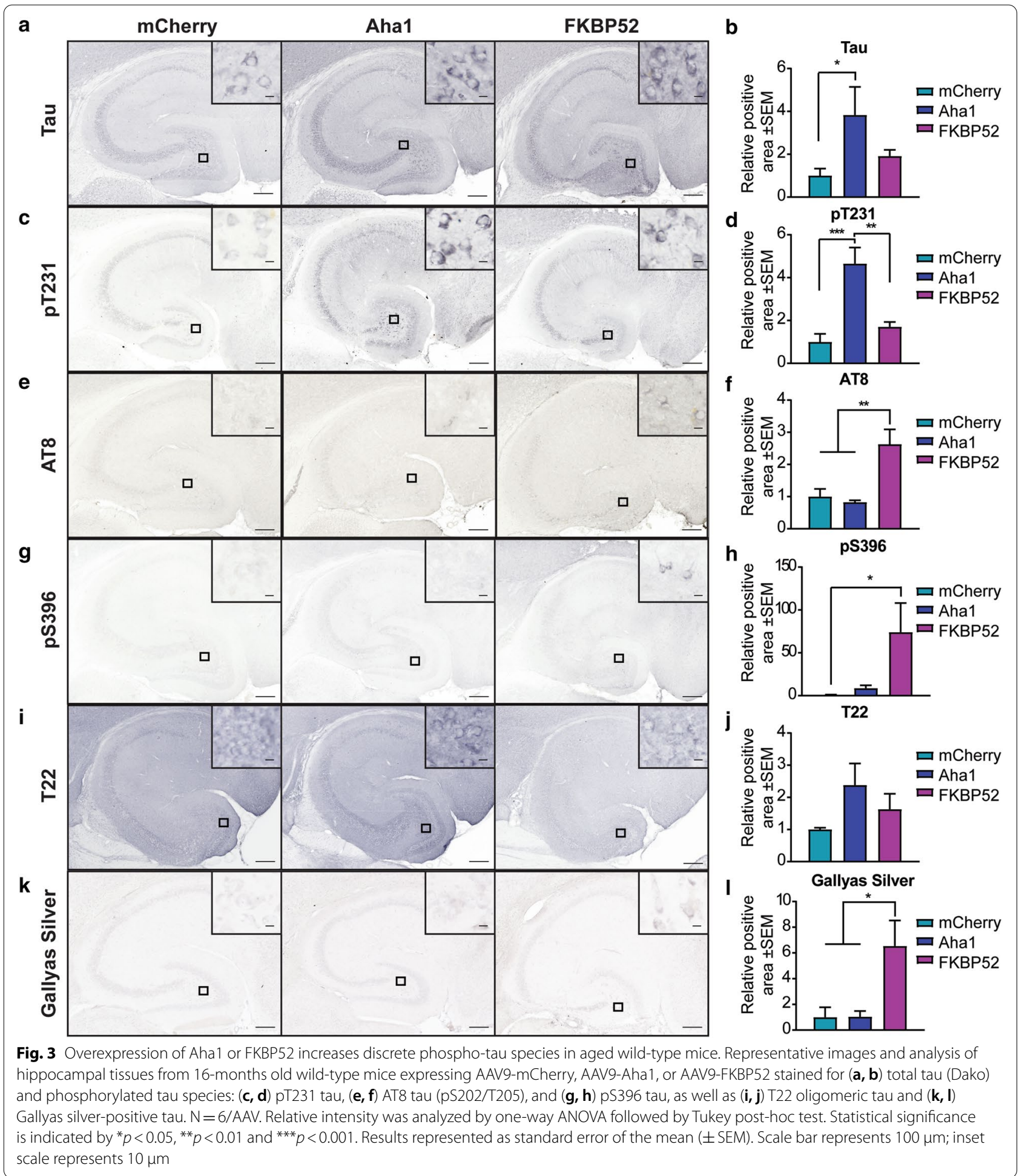

AT8 tau in the hippocampus, we also examined its expression in these cortices. FKBP52 increased the levels of this phospho-tau species in the subiculum (Fig. 8a), which was also the area showing the highest induction in markers of
GFAP (Fig. 8b) and IBA1 (Fig. 8c) driven by FKBP52. Data indicate that FKBP52 contributes not only to the induction of these glial cells and tau accumulation but also the spreading of these pathologies in the brain. 


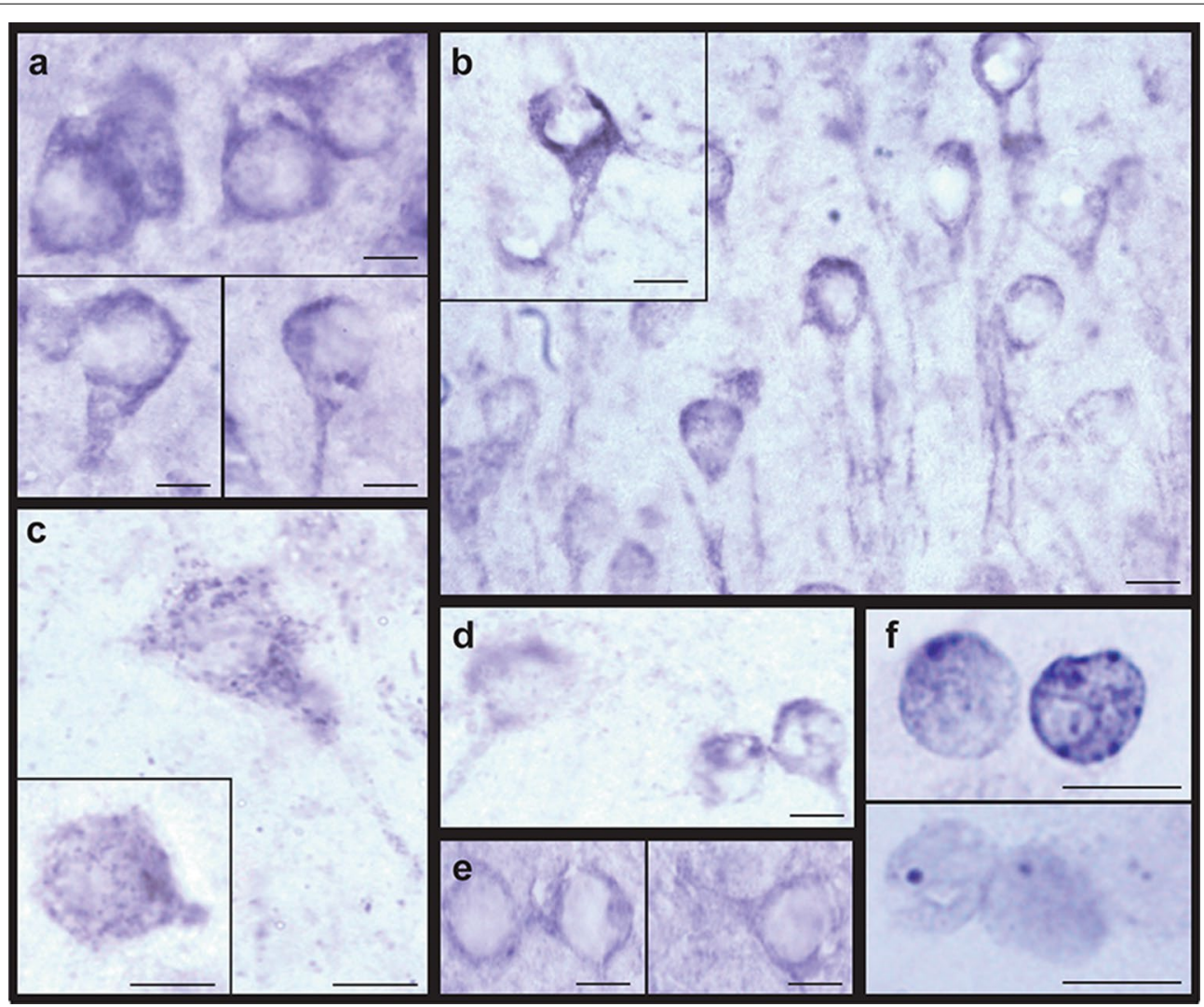

Fig. 4 Examples of tau accumulation in the hippocampus of aged wild-type mice following overexpression of Aha1 or FKBP52. High magnification images (100x) were obtained from the hippocampus of a representative animal in the group with the highest tau accumulation. Representative images of tau species and their respective groups are the following: (a) total tau (Dako; AAV9-Aha1), (b) pT231 tau (AAV9-Aha1), (c) AT8 tau (pS202/ T205; AAV9-FKBP52), (d) pS396 tau (AAV9-FKBP52), (e) T22 (AAV9-Aha1), and (f) Gallyas-silver (AAV9-FKBP52). Scale bar represents $10 \mu \mathrm{m}$
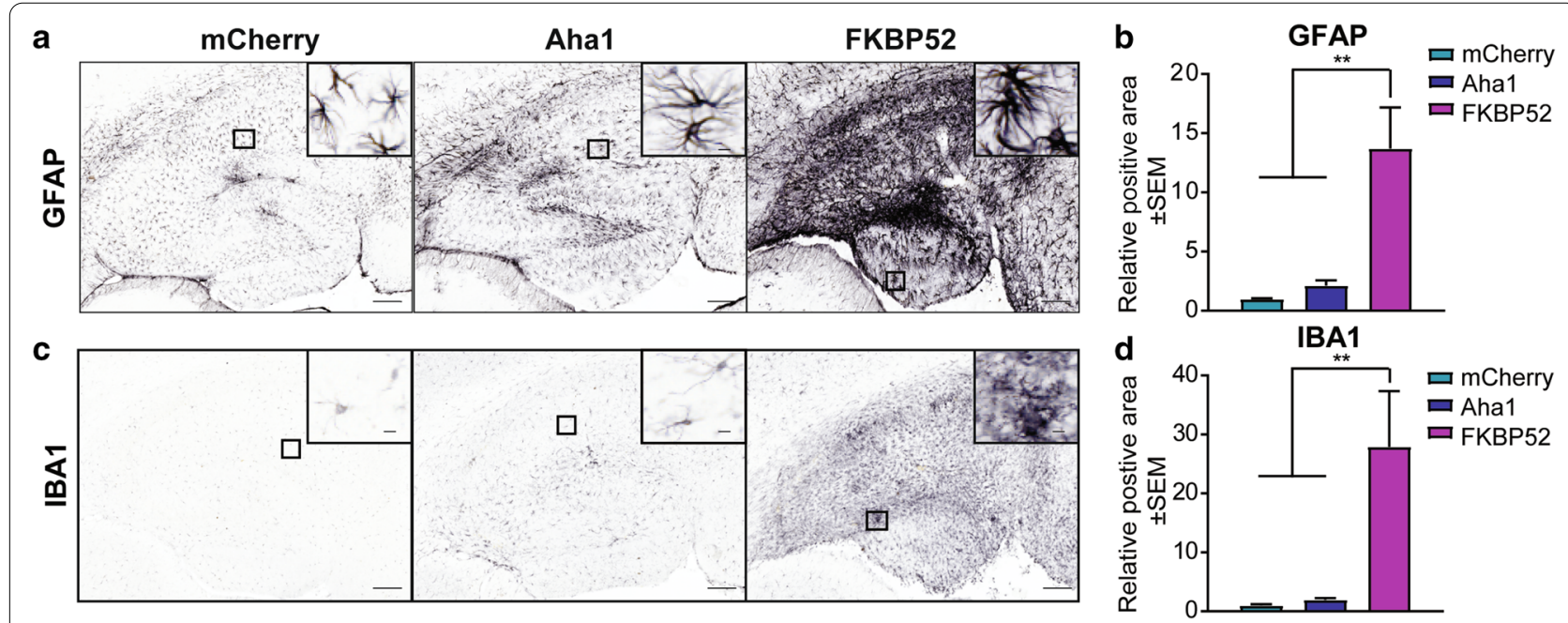

Fig. 5 FKBP52 promotes activation of astrocytes and microglia in aged wild-type mice. Representative images and analysis of hippocampal tissues from 16-month-old wild-type mice expressing AAV9-mCherry, AAV9-Aha1, or AAV9-FKBP52 stained for (a, b) astrocyte marker (GFAP) and (c, d) microglial marker (IBA1). $N=6 / A A V$. Relative intensity was analyzed by one-way ANOVA followed by Tukey post-hoc test. Statistical significance is indicated by ${ }^{* *} p<0.01$. Results represented as standard error of the mean ( \pm SEM). Scale bar represents $100 \mu \mathrm{m}$; inset scale represents $10 \mu \mathrm{m}$ 


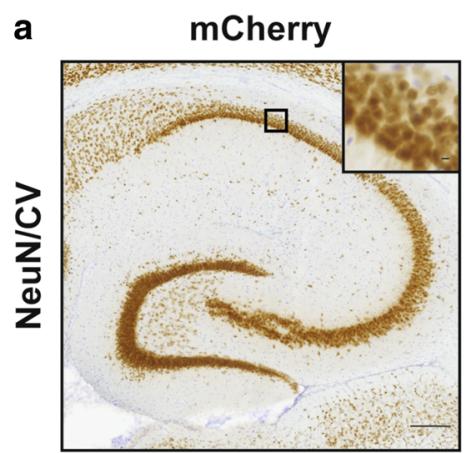

b

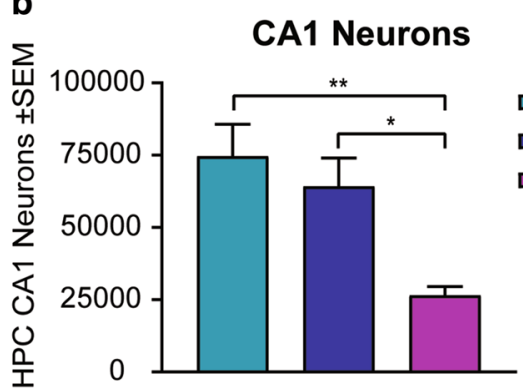

Aha1

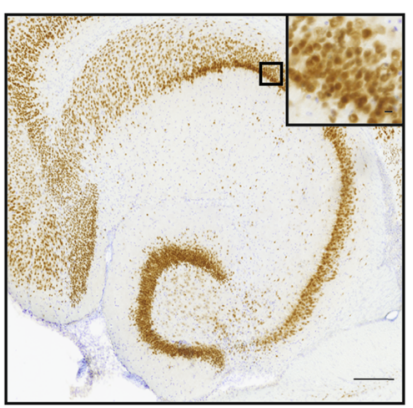

c
FKBP52

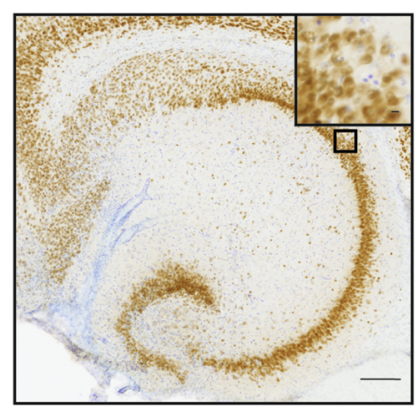

CA1 Volume
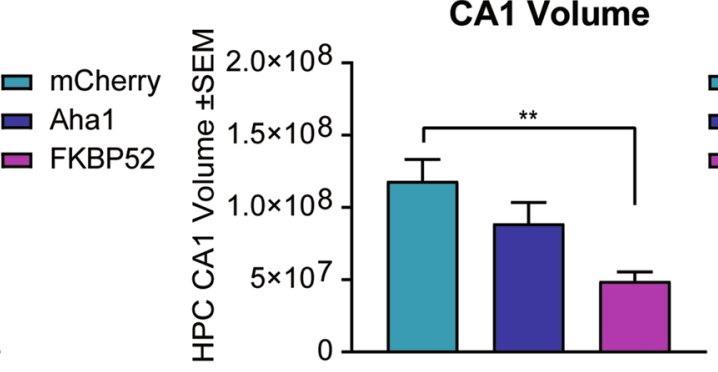

Fig. 6 Overexpression of FKBP52 promotes neurotoxicity in aged wild-type mice. (a) Representative images from hippocampal neurons stained with NeuN (brown) and cresyl violet (purple). These hippocampal slices correspond to AAV9-mCherry, AAV9-Aha1, and AAV9-FKBP52 injected wild-type mice. Quantification of CA1 hippocampal (b) neuronal density and (c) volume using unbiased stereology from these animals. $N=6 / A A V$. Results represent the standard error of the mean $\left( \pm\right.$ SEM). Data was analyzed by a one-way ANOVA followed by Tukey post-hoc test. ${ }^{*} p<0.05$ and ${ }^{* *} p<0.01$ is considered statistical difference in neuronal loss. Scale bars $=100 \mu \mathrm{m}$ and inset scale represents $10 \mu \mathrm{m}$. CV, cresyl violet; CA1, Cornu ammonis subfield $1 ;$ HPC, hippocampus

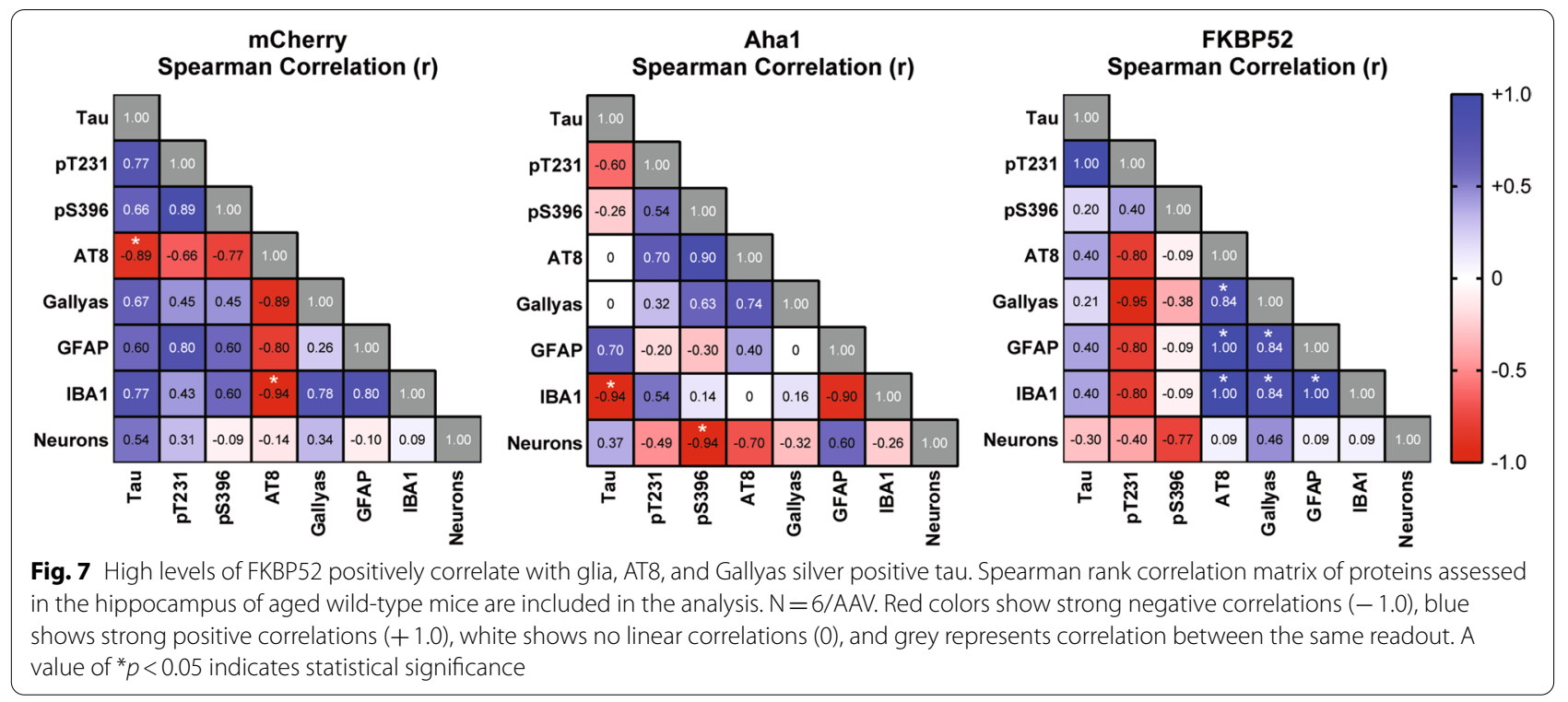

\section{Discussion}

The impact of high levels of Aha1 or FKBP52 in the aged brain was examined in this study. We showed that high expression of either chaperone increases pathological tau species in 16-month-old wild-type mice. We also found that Aha1 overexpression impaired associative learning while FKBP52 overexpression caused deficits in cognitive flexibility during spatial learning. In addition, high 


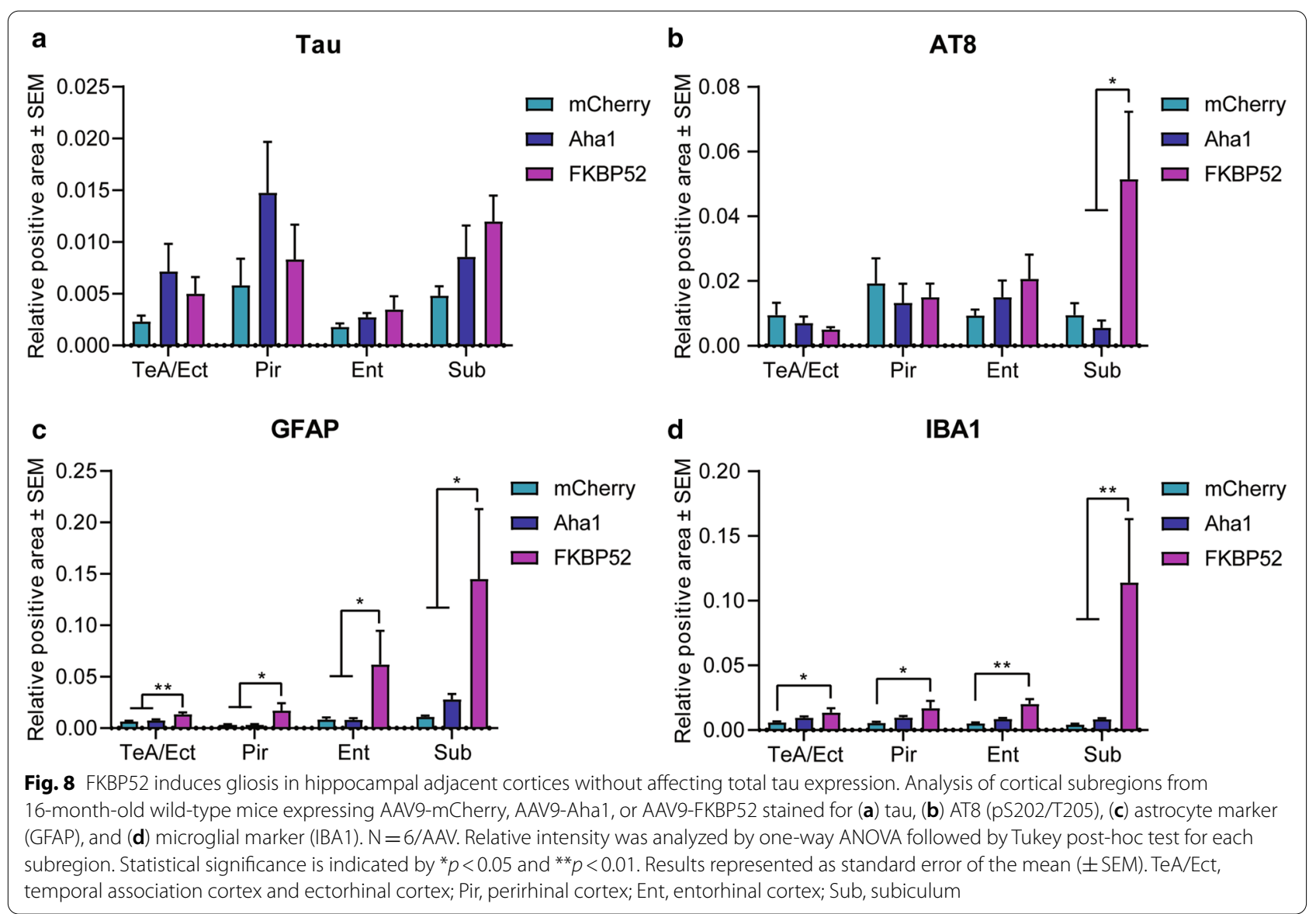

FKBP52 levels evoked a significant neuroinflammatory response of both GFAP and IBA1 not only in the hippocampus, but in cortical areas adjacent to the injection site where tau was also found to accumulate. We found a strong correlation between levels of FKBP52, glial cell markers, and AT8 tau, which may be key players driving the neuronal loss and cognitive deficits observed in these mice.

Most preclinical studies have focused on recapitulating tau pathology in vitro or by using transgenic mice $[39,40,60]$. Although these strategies have been very valuable for understanding biological mechanisms underlying the disease, their translatability in clinical trials has been questioned [25, 39]. Our study excluded the most common limitations and confounding effects of using tau transgenic mouse models, which include the insertion of transgenes, the deletion of endogenous genes, the overexpression of tau, the inclusion of tau mutations, and the limited ability to evaluate age-dependent neurodegeneration. Another advantage presented in this study is the ability to maintain a longterm stable expression of these chaperones in neurons starting at specific timepoints by AAV9 transduction.
This initiated a pathogenic cascade that involved tau accumulation instead of tau being the initiating event, which may better represent the tauopathic brain in diseases, like $A D$, which are absent of tau mutations and total tau levels are unchanged. Our results are highly relevant to age-related effects in normal and pathological aging, since tau pathology can occur in the brains of individuals from both groups [30]. Prior studies from our group revealed that Aha1 and FKBP52 chaperones also promote the accumulation of tau in $\mathrm{rTg} 4510$ tau transgenic mice $[19,90]$. However, in these studies, no significant effects of Aha1 or FKBP52 overexpression on cognition or pathology were observed in young wild-type mice. This really highlights the importance of the aging component, since short-term (2-3 month) overexpression of these molecular chaperones in younger (5-6 month) animals did not initiate pathogenesis as in our current study.

Our findings suggest that chaperone imbalance could initiate and promote neurodegeneration in aged wildtype mice via two pathways: by inducing tau accumulation and by promoting a neuroinflammatory state in the hippocampus. These processes are interconnected; hence 
they can evoke a feedforward loop once activated [61]. Both Aha1 and FKBP52 increased phosphorylation of discrete tau species. However, only FKBP52 overexpression caused neurodegeneration, suggesting that FKBP52 initiates a more aggressive pathological cascade. FKBP52 overexpression increased AT8 and pS396 phospho-tau species as well as argyrophilic-like tau-positive signal. Based on our examination, FKBP52 may participate in the pre-tangle stage by inducing structural features often described in stages preceding neurofibrillary tangle formation when neuronal loss is occurring [60, 61, 98]. Some of our observations include the presence of the perinuclear accumulation of total and phospho-tau species, diffuse and granular tau immunoreactivity, and argyrophilic-like grains. However, no tau tangles were observed. We may not see tangles in these brains because of the biological differences between human and murine tau. The normal evolution from pre-tangles to mature neurofibrillary tangles requires a shift between two tau isoforms: the 3R and 4R [99]. Different from humans, adult mouse brain lacks $3 R$ tau, which is thought to be needed for maturity of fibrils and tangles in $\mathrm{AD}[47,99]$.

Since FKBP52 levels were reported as low at advanced pathological stages [38], based on what this study revealed perhaps this is caused by the loss of neurons expressing high levels FKBP52 earlier in the disease. A heighten inflammatory response is likely also contributing to the neurotoxicity in the FKBP52 injected wild-type mice. This stimulation could be through FKBP52- or taumediated mechanisms. FKBP52 is known to promote a proinflammatory environment through the activation of the NF-KB and the IL-6 cytokine [29]. Increased levels of these proteins may be responsible for inducing GFAP and IBA1 [94], correlating with our observations in mice receiving FKBP52 injections. FKBP52 also potentiated activation of glial cells in areas adjacent to the hippocampus escalating the hippocampal-cortical damage. These observations indicate that FKBP52 may be responsible for maintaining a continuous inflammatory state by promoting proinflammatory markers, which may lead to the release of neurotoxic factors from astrocytes and microglia [64], ultimately causing neuronal damage.

Because FKBP52 and Aha1 are both co-chaperones of Hsp90, disequilibrium or disruption of existing Hsp90 chaperone heterocomplexes may be another factor contributing to the pathogenesis in these mice. FKBP52 competes for binding the tetratricopeptide repeat (TPR) domain of Hsp90 with other co-chaperones including FKBP51, Cyp40, and CHIP $[8,75]$. The effect of FKBP52 on tau accumulation may be exacerbated by the displacement of these other chaperones, since some co-chaperones, like Cyp40 and CHIP, have been shown to prevent tau accumulation $[5,23]$.
Although Aha1 binds to a distinct region of Hsp90, Aha1 has been shown to regulate the binding of other co-chaperones to Hsp90 by preventing the binding of HOP, p50, and Cdc37 [41, 96]. Hsp90 heterocomplexes are key regulators of steroid hormone receptors. The GR complex, for example, is regulated by FKBP52 levels. FKBP52 promotes its nuclear translocation while competing with FKBP51, which slows GR transactivation [97]. This will not only generate a greater GR-driven response to stress, but also promotes transcription of pro-inflammatory cytokines [7]. Binding of HOP, Hsp70, and p23 clients to Hsp90-FKBP52GR complex can also determine the steroid receptor maturation and activity affecting stress response as well as the chaperone interaction with tau $[48,85]$. Interestingly, Aha1 competes with GR for Hsp90 binding site, ultimately inhibiting GR activity $[66,80]$. This may explain the lower inflammatory reaction in Aha1 injected animals, despite the increase in pT231 tau. Further studies must examine how these chaperone heterocomplexes are affected and if there is a feedforward potentiation among specific chaperones, tau, and glial activation.

Declined proteostasis in aging limits the chaperone capacity to remodel proteins to their native form or direct them towards degradation [56]. We know that, in the hyperphosphorylated state, tau undergoes polyubiquitination, but evades degradation by the proteasome [51]. Thus, it is possible that FKBP52-induced levels of phospho-tau species intensified the burden on the aged proteostasis system, causing the neurotoxicity and neuronal loss seen in this study. This is in line with a previous study implicating a role for FKBP52 in neuronal health where overexpression of FKBP52, not only destabilizes microtubules by affecting tau, but also reduces neurite outgrowth in PC12 cells $[17,18]$. The effects we measured on tau and neuronal loss could also be an indication of failure in other degradation systems, like the autophagy system [57], since others have reported tau accumulation, neuroinflammation and neuronal loss in mice lacking the autophagy protein, Atg16L1 [46].

Future research is needed to address the current limitations of this study. First, the limited number of aged animals that were available to use for this study makes it difficult to evaluate sex differences due the small representation of sex in each group. Increasing the sample size will provide further confidence in the behavioral and pathological effects described here as well as allow for the examination of sex-difference. Second, it is difficult to determine the order of events by which FKBP52 causes neuronal loss. By assessing earlier timepoints after AAV9 injections in aged wild-type as well as in tau knockout mice, the timing and relationship 
between tau phosphorylation, inflammation, and neuronal loss could be examined. Third, we were expecting an accumulation of tau oligomers by Aha1 and FKBP52, based on our prior studies in tau transgenic mice $[19,90]$. Failure to detect these oligomers may be due methodological limitations since the use of these antibodies on mouse tau has not been characterized. Further testing of specific antibodies against mouse tau oligomers is needed to confirm the null effect on oligomers. Fourth, examining how other Hsp90 heterocomplexes may be affected by high levels of FKBP52 or Aha1 would provide important information about how declined proteostasis is sustained during aging. Fifth, testing additional molecular chaperones may reveal members that drive unique pathologies as well as discrete chaperones absent of any effect, which could be used as controls in future studies. Lastly, we observed a significant silver-positive signal in FKBP52 injected mice without the formation of true tau tangles. Additional studies are needed to determine if FKBP52 overexpression could drive tangles at later timepoints in aged wild-type mice or if the lack of $3 R$ tau in the aged mouse brain prevents mature tangle formation [47]. It is possible that this pathology may only be generated by FKBP52 in mice expressing human tau.

In conclusion, our findings demonstrate that imbalances in molecular chaperones can have a significant impact on the pathogenic accumulation of endogenous tau in the aged mouse brain. Both Aha1 and FKBP52 altered tau accumulation and cognition, but only FKBP52 induced gliosis in the hippocampus and adjacent brain cortices. Our discoveries suggest that FKBP52 may aggressively promote changes in tau, activate glial cells, and this in turn may cause a neurotoxic environment for neurons. The initiation of these pathologies in one brain region caused aberrant accumulation in connected brain regions, which may model the prion-like spreading of tau that has been described in AD. This demonstrates that disturbances in molecular chaperone proteins in an aged wild-type mouse brain models key features of AD-like pathogenesis.

\section{Supplementary Information}

The online version contains supplementary material available at https://doi. org/10.1186/s40478-021-01159-w.

Additional file 1. Fig. S1: Overexpression of Aha1 or FKBP52 increases discrete phospho-tau species in aged wild-type mice. Additional insets from Figure 3 showing the CA1, CA3, and dentate gyrus (DG) from 16-months old wild-type mice expressing AAV9-mCherry, AAV9-Aha1, or AAV9-FKBP52 stained for (a) total tau (Dako), (b) pT231 tau, (c) AT8 (pS202/ T205) tau, and (d) pS396 tau, as well as (e) T22 oligomeric tau and (f) Gallyas silver-positive tau. Scale bar represents $10 \mu \mathrm{m}$

\section{Acknowledgements}

Research reported in this publication was supported by the National Institutes of Health/National Institute of Neurological Disorders and Stroke R01 NS073899, National Institutes of Aging RF1 AG055088, and National Institute of Mental Health R01 MH103848. The content is solely the responsibility of the authors and does not necessarily represent the official views of the National Institutes of Health. This work was also supported in part by Merit Review Award 101 BX004626 from the United States (U.S.) Department of Veterans Affairs Biomedical Laboratory Research and Development Service. The views expressed in this article are those of the authors and do not necessarily reflect the position, policy or views of the Department of Veterans Affairs or the United States Government. Support was also provided by the Alzheimer's Association award 2019-AARFD-644407.

\section{Authors' contributions}

Conceptualization, original draft preparation, and writing, MC-M, NTG, and LJB; Behavioral testing and analysis, LAG; Mice surgery and viral injections, JDB; Histopathological and immunohistochemistry analysis, MC-M, NTG, LAG, and DMB; Stereology, DMB; Mice breeding and genotyping, DBA; Resources and funding acquisition, LJB; Supervision and project administration, LJB All authors read and approved the final manuscript. MC-M and NTG have contributed equally to this work.

\section{Funding}

Research reported in this publication was supported by the National Institutes of Health/National Institute of Neurological Disorders and Stroke R01 NS073899, National Institutes of Aging RF1 AG055088, and National Institute of Mental Health R01 MH103848. The content is solely the responsibility of the authors and does not necessarily represent the official views of the National Institutes of Health. This work was also supported in part by Merit Review Award 101 BX004626 from the United States (U.S.) Department of Veterans Affairs Biomedical Laboratory Research and Development Service. The views expressed in this article are those of the authors and do not necessarily reflect the position, policy or views of the Department of Veterans Affairs or the United States Government. Support was also provided by the Alzheimer's Association award 2019-AARFD-644407.

\section{Availability of data and materials}

The datasets used and/or analyzed during the current study are available from the corresponding author on reasonable request.

\section{Declarations}

\section{Ethical approval}

All studies were carried out following the guidelines set by the University of South Florida's Institutional Animal Care and Use Committee in accordance with the Association for Assessment and Accreditation of Laboratory Animal Care International regulations.

\section{Consent for publication}

Not applicable.

\section{Competing interests}

The authors declare that they have no competing interests.

\section{Author details}

${ }^{1}$ USF Health Byrd Alzheimer's Institute, University of South Florida, Tampa, FL 33613, USA. ${ }^{2}$ Department of Molecular Medicine, Morsani College of Medicine, University of South Florida, Tampa, FL 33620, USA. ${ }^{3}$ Research Service, James A Haley Veterans Hospital, 13000 Bruce B Downs Blvd, Tampa, FL 33612, USA.

Received: 4 February 2021 Accepted: 15 March 2021

Published online: 08 April 2021

\section{References}

1. Armstrong RA (2019) Risk factors for Alzheimer's disease. Folia Neuropathol 57:87-105. https://doi.org/10.5114/fn.2019.85929 
2. Abisambra JF, Jinwal UK, Blair L, O'Leary JC 3rd, Li Q, Brady S, Wang L, Guidi CE, Zhang B, Nordhues BA et al (2013) Tau accumulation activates the unfolded protein response by impairing endoplasmic reticulumassociated degradation. J Neurosci 33:9498-9507. https://doi.org/10. 1523/JNEUROSCI.5397-12.2013

3. Andorfer C, Kress Y, Espinoza M, de Silva R, Tucker KL, Barde YA, Duff K, Davies P (2003) Hyperphosphorylation and aggregation of tau in mice expressing normal human tau isoforms. J Neurochem 86:582-590. https://doi.org/10.1046/j.1471-4159.2003.01879.x

4. Arriagada PV, Growdon JH, Hedley-Whyte ET, Hyman BT (1992) Neurofibrillary tangles but not senile plaques parallel duration and severity of Alzheimer's disease. Neurology 42:631-639

5. Baker JD, Shelton LB, Zheng D, Favretto F, Nordhues BA, Darling A, Sullivan LE, Sun Z, Solanki PK, Martin MD et al (2017) Human cyclophilin 40 unravels neurotoxic amyloids. PLoS Biol 15:e2001336. https://doi.org/ 10.1371/journal.pbio.2001336

6. Bamberger CM, Wald M, Bamberger AM, Schulte HM (1997) Inhibition of mineralocorticoid and glucocorticoid receptor function by the heat shock protein 90-binding agent geldanamycin. Mol Cell Endocrinol 131:233-240. https://doi.org/10.1016/s0303-7207(97)00115-9

7. Bancher C, Jellinger K, Lassmann H, Fischer P, Leblhuber F (1996) Correlations between mental state and quantitative neuropathology in the Vienna Longitudinal Study on Dementia. Eur Arch Psychiatry Clin Neurosci 246:137-146. https://doi.org/10.1007/BF02189115

8. Barent RL, Nair SC, Carr DC, Ruan Y, Rimerman RA, Fulton J, Zhang Y, Smith DF (1998) Analysis of FKBP51/FKBP52 chimeras and mutants for Hsp90 binding and association with progesterone receptor complexes. Mol Endocrinol 12:342-354. https://doi.org/10.1210/mend. 12.3.0075

9. Beach TG, Walker R, McGeer EG (1989) Patterns of gliosis in Alzheimer's disease and aging cerebrum. Glia 2:420-436. https://doi.org/10.1002/ glia.440020605

10. Biebl MM, Riedl M, Buchner J (2020) Hsp90 Co-chaperones form plastic genetic networks adapted to client maturation. Cell Rep 32:108063. https://doi.org/10.1016/..celrep.2020.108063

11. Blair LJ, Nordhues BA, Hill SE, Scaglione KM, O'Leary JC 3rd, Fontaine SN, Breydo L, Zhang B, Li P, Wang L et al (2013) Accelerated neurodegeneration through chaperone-mediated oligomerization of tau. J Clin Invest 123:4158-4169. https://doi.org/10.1172/JCl69003

12. Blair LJ, Sabbagh JJ, Dickey CA (2014) Targeting Hsp90 and its COchaperones to treat Alzheimer's disease. Expert Opin Ther Targets 18:1219-1232. https://doi.org/10.1517/14728222.2014.943185

13. Braak H, Braak E (1991) Neuropathological stageing of Alzheimerrelated changes. Acta Neuropathol (Berl) 82:239-259

14. Brehme M, Voisine C, Rolland T, Wachi S, Soper JH, Zhu Y, Orton K, Villella A, Garza D, Vidal M et al (2014) A chaperome subnetwork safeguards proteostasis in aging and neurodegenerative disease. Cell Rep 9:1135-1150. https://doi.org/10.1016/j.celrep.2014.09.042

15. Brehmer D, Rudiger S, Gassler CS, Klostermeier D, Packschies L, Reinstein J, Mayer MP, Bukau B (2001) Tuning of chaperone activity of Hsp70 proteins by modulation of nucleotide exchange. Nat Struct Biol 8:427-432. https://doi.org/10.1038/87588

16. Carty N, Lee D, Dickey C, Ceballos-Diaz C, Jansen-West K, Golde TE, Gordon MN, Morgan D, Nash K (2010) Convection-enhanced delivery and systemic mannitol increase gene product distribution of AAV vectors 5, 8, and 9 and increase gene product in the adult mouse brain. J Neurosci Methods 194:144-153. https://doi.org/10.1016/j.jneumeth. 2010.10.010

17. Chambraud B, Belabes H, Fontaine-Lenoir V, Fellous A, Baulieu EE (2007) The immunophilin FKBP52 specifically binds to tubulin and prevents microtubule formation. FASEB J 21:2787-2797. https://doi.org/10.1096/ f. $06-7667 \mathrm{com}$

18. Chambraud B, Sardin E, Giustiniani J, Dounane O, Schumacher M, Goedert M, Baulieu EE (2010) A role for FKBP52 in Tau protein function. Proc Natl Acad Sci USA 107:2658-2663. https://doi.org/10.1073/pnas.09149 57107

19. Criado-Marrero M GN, Gould LA, Blazier DM, Vidal Aguiar Y, Smith TM, Abdelmaboud SS, Shelton LB, Wang X, Dahrendorff J, BeaulieuAbdelahad D, Dickey CA, Blair $L J$ (in press) FKBP52 overexpression accelerates hippocampal-dependent memory impairments in a tau transgenic mouse model. npj Aging Mech Dis. https://doi.org/10.1038/ s41514-021-00062-x

20. Daily JL, Nash K, Jinwal U, Golde T, Rogers J, Peters MM, Burdine RD, Dickey C, Banko JL, Weeber EJ (2011) Adeno-associated virus-mediated rescue of the cognitive defects in a mouse model for Angelman syndrome. PLOS ONE 6:e27221. https://doi.org/10.1371/journal.pone. 0027221

21. DeVos SL, Corjuc BT, Oakley DH, Nobuhara CK, Bannon RN, Chase A, Commins C, Gonzalez JA, Dooley PM, Frosch MP et al (2018) Synaptic tau seeding precedes tau pathology in human Alzheimer's disease brain. Front Neurosci 12:267. https://doi.org/10.3389/fnins.2018.00267

22. Dickey C, Kraft C, Jinwal U, Koren J, Johnson A, Anderson L, Lebson L, Lee D, Dickson D, de Silva R et al (2009) Aging analysis reveals slowed tau turnover and enhanced stress response in a mouse model of tauopathy. Am J Pathol 174:228-238. https://doi.org/10.2353/ajpath. 2009.080764

23. Dickey CA, Kamal A, Lundgren K, Klosak N, Bailey RM, Dunmore J, Ash P, Shoraka S, Zlatkovic J, Eckman CB et al (2007) The high-affinity HSP90CHIP complex recognizes and selectively degrades phosphorylated tau client proteins. J Clin Invest 117:648-658

24. Dominguez-Alvaro M, Montero-Crespo M, Blazquez-Llorca L, Insausti R, DeFelipe J, Alonso-Nanclares L (2018) Three-dimensional analysis of synapses in the transentorhinal cortex of Alzheimer's disease patients. Acta Neuropathol Commun 6:20. https://doi.org/10.1186/ s40478-018-0520-6

25. Drummond E, Wisniewski T (2017) Alzheimer's disease: experimental models and reality. Acta Neuropathol 133:155-175. https://doi.org/10 1007/s00401-016-1662-x

26. Duque S, Joussemet B, Riviere C, Marais T, Dubreil L, Douar AM, Fyfe J, Moullier P, Colle MA, Barkats M (2009) Intravenous administration of self-complementary AAV9 enables transgene delivery to adult motor neurons. Mol Ther 17:1187-1196. https://doi.org/10.1038/mt.2009.71

27. Echeverria PC, Picard D (2010) Molecular chaperones, essential partners of steroid hormone receptors for activity and mobility. Biochim Biophys Acta 1803:641-649. https://doi.org/10.1016/j.bbamcr.2009.11.012

28. Ehrenberg AJ, Suemoto CK, Franca Resende EP, Petersen C, Leite REP, Rodriguez RD, Ferretti-Rebustini REL, You M, Oh J, Nitrini R et al (2018) Neuropathologic correlates of psychiatric symptoms in Alzheimer's disease. J Alzheimers Dis 66:1 15-126. https://doi.org/10.3233/JAD-180688

29. Erlejman AG, De Leo SA, Mazaira GI, Molinari AM, Camisay MF, Fontana V, Cox MB, Piwien-Pilipuk G, Galigniana MD (2014) NF-kappaB transcriptional activity is modulated by FK506-binding proteins FKBP51 and FKBP52: a role for peptidyl-prolyl isomerase activity. J Biol Chem 289:26263-26276. https://doi.org/10.1074/jbc.M114.582882

30. Fjell AM, McEvoy L, Holland D, Dale AM, Walhovd KB, Alzheimer's Disease Neuroimaging I (2014) What is normal in normal aging? Effects of aging, amyloid and Alzheimer's disease on the cerebral cortex and the hippocampus. Prog Neurobiol 117:20-40. https://doi.org/10.1016/j. pneurobio.2014.02.004

31. Foust KD, Nurre E, Montgomery CL, Hernandez A, Chan CM, Kaspar BK (2009) Intravascular AAV9 preferentially targets neonatal neurons and adult astrocytes. Nat Biotechnol 27:59-65. https://doi.org/10.1038/nbt. 1515

32. Frautschy SA, Baird A, Cole GM (1991) Effects of injected Alzheimer beta-amyloid cores in rat brain. Proc Natl Acad Sci USA 88:8362-8366

33. Fu H, Possenti A, Freer R, Nakano Y, Hernandez Villegas NC, Tang M, Cauhy PVM, Lassus BA, Chen S, Fowler SL et al (2019) A tau homeostasis signature is linked with the cellular and regional vulnerability of excitatory neurons to tau pathology. Nat Neurosci 22:47-56. https://doi.org/ 10.1038/s41593-018-0298-7

34. Galigniana MD, Erlejman AG, Monte M, Gomez-Sanchez C, PiwienPilipuk G (2010) The hsp90-FKBP52 complex links the mineralocorticoid receptor to motor proteins and persists bound to the receptor in early nuclear events. Mol Cell Biol 30:1285-1298. https://doi.org/10.1128/ MCB.01190-09

35. Gamache J, Benzow K, Forster C, Kemper L, Hlynialuk C, Furrow E, Ashe KH, Koob MD (2019) Factors other than hTau overexpression that contribute to tauopathy-like phenotype in rTg4510 mice. Nat Commun 10:2479. https://doi.org/10.1038/s41467-019-10428-1

36. Giustiniani J, Chambraud B, Sardin E, Dounane O, Guillemeau K, Nakatani H, Paquet D, Kamah A, Landrieu I, Lippens G et al (2014) 
Immunophilin FKBP52 induces Tau-P301L filamentous assembly in vitro and modulates its activity in a model of tauopathy. Proc Natl Acad Sci USA 111:4584-4589. https://doi.org/10.1073/pnas.1402645111

37. Giustiniani J, Guillemeau K, Dounane O, Sardin E, Huvent I, Schmitt A, Hamdane M, Buee L, Landrieu I, Lippens G et al (2015) The FK506binding protein FKBP52 in vitro induces aggregation of truncated Tau forms with prion-like behavior. FASEB J 29:3171-3181. https://doi.org/ 10.1096/f.14-268243

38. Giustiniani J, Sineus M, Sardin E, Dounane O, Panchal M, Sazdovitch V, Duyckaerts C, Chambraud B, Baulieu EE (2012) Decrease of the immunophilin FKBP52 accumulation in human brains of Alzheimer's disease and FTDP-17. J Alzheimers Dis 29:471-483. https://doi.org/10.3233/ JAD-2011-111895

39. Gotz J, Bodea LG, Goedert M (2018) Rodent models for Alzheimer disease. Nat Rev Neurosci 19:583-598. https://doi.org/10.1038/ s41583-018-0054-8

40. Gulyaeva NV, Bobkova NV, Kolosova NG, Samokhin AN, Stepanichev MY, Stefanova NA (2017) Molecular and cellular mechanisms of sporadic Alzheimer's disease: studies on rodent models in vivo. Biochemistry (Mosc) 82:1088-1102. https://doi.org/10.1134/S0006297917100029

41. Harst A, Lin H, Obermann WM (2005) Aha1 competes with Hop, p50 and p23 for binding to the molecular chaperone Hsp90 and contributes to kinase and hormone receptor activation. Biochem J 387:789796. https://doi.org/10.1042/BJ20041283

42. Hartl FU, Bracher A, Hayer-Hartl M (2011) Molecular chaperones in protein folding and proteostasis. Nature 475:324-332. https://doi.org/ 10.1038/nature 10317

43. Hashimoto S, Matsuba Y, Kamano N, Mihira N, Sahara N, Takano J, Muramatsu SI, Saido TC, Saito T (2019) Tau binding protein CAPON induces tau aggregation and neurodegeneration. Nat Commun 10:2394. https://doi.org/10.1038/s41467-019-10278-x

44. He Z, McBride JD, Xu H, Changolkar L, Kim SJ, Zhang B, Narasimhan S, Gibbons GS, Guo JL, Kozak M et al (2020) Transmission of tauopathy strains is independent of their isoform composition. Nat Commun 11:7. https://doi.org/10.1038/s41467-019-13787-x

45. Hebert LE, Weuve J, Scherr PA, Evans DA (2013) Alzheimer disease in the United States (2010-2050) estimated using the 2010 census. Neurology 80:1778-1783. https://doi.org/10.1212/WNL.0b013e31828726f5

46. Heckmann BL, Teubner BJW, Boada-Romero E, Tummers B, Guy C, Fitzgerald P, Mayer U, Carding S, Zakharenko SS, Wileman T et al (2020) Noncanonical function of an autophagy protein prevents spontaneous Alzheimer's disease. Sci Adv 6:eabb9036. https://doi.org/10.1126/sciadv. abb9036

47. Hernandez F, Merchan-Rubira J, Valles-Saiz L, Rodriguez-Matellan A, Avila J (2020) Differences between human and murine tau at the $\mathrm{N}$-terminal end. Front Aging Neurosci 12:11. https://doi.org/10.3389/ fnagi.2020.00011

48. Hildenbrand ZL, Molugu SK, Herrera N, Ramirez C, Xiao C, Bernal RA (2011) Hsp90 can accommodate the simultaneous binding of the FKBP52 and HOP proteins. Oncotarget 2:43-58. https://doi.org/10. 18632/oncotarget.225

49. Iba M, Guo JL, McBride JD, Zhang B, Trojanowski JQ, Lee VM (2013) Synthetic tau fibrils mediate transmission of neurofibrillary tangles in a transgenic mouse model of Alzheimer's-like tauopathy. J Neurosci 33:1024-1037. https://doi.org/10.1523/JNEUROSCI.2642-12.2013

50. Ingelsson M, Fukumoto H, Newell KL, Growdon JH, Hedley-Whyte ET, Frosch MP, Albert MS, Hyman BT, Irizarry MC (2004) Early Abeta accumulation and progressive synaptic loss, gliosis, and tangle formation in AD brain. Neurology 62:925-931. https://doi.org/10.1212/01.wnl.00001 15115.98960 .37

51. Iqbal K, Liu F, Gong CX, Alonso Adel C, Grundke-lqbal I (2009) Mechanisms of tau-induced neurodegeneration. Acta Neuropathol 118:53-69. https://doi.org/10.1007/s00401-009-0486-3

52. Jankowsky JL, Zheng H (2017) Practical considerations for choosing a mouse model of Alzheimer's disease. Mol Neurodegener 12:89. https:// doi.org/10.1186/s13024-017-0231-7

53. Jinwal UK, O'Leary JC 3rd, Borysov SI, Jones JR, Li Q, Koren J 3rd, Abisambra JF, Vestal GD, Lawson LY, Johnson AG et al (2010) Hsc70 rapidly engages tau after microtubule destabilization. J Biol Chem 285:16798-16805. https://doi.org/10.1074/jbc.M110.113753
54. Kahlson MA, Colodner KJ (2015) Glial tau pathology in tauopathies: functional consequences. J Exp Neurosci 9:43-50. https://doi.org/10. 4137/JEN.S25515

55. Kim YE, Hipp MS, Bracher A, Hayer-Hartl M, Hartl FU (2013) Molecular chaperone functions in protein folding and proteostasis. Annu Rev Biochem 82:323-355. https://doi.org/10.1146/annurev-bioch em-060208-092442

56. Klaips CL, Jayaraj GG, Hartl FU (2018) Pathways of cellular proteostasis in aging and disease. J Cell Biol 217:51-63. https://doi.org/10.1083/jcb. 201709072

57. Komatsu M, Waguri S, Chiba T, Murata S, Iwata J, Tanida I, Ueno T, Koike M, Uchiyama Y, Kominami E et al (2006) Loss of autophagy in the central nervous system causes neurodegeneration in mice. Nature 441:880-884. https://doi.org/10.1038/nature04723

58. Koopman MB, Rüdiger SGD (2020) Alzheimer cells on their way to derailment show selective changes in protein quality control network. Front Mol Biosci. https://doi.org/10.3389/fmolb.2020.00214

59. Koulov AV, LaPointe P, Lu B, Razvi A, Coppinger J, Dong MQ, Matteson J, Laister R, Arrowsmith C, Yates JR 3rd et al (2010) Biological and structural basis for Aha1 regulation of Hsp90 ATPase activity in maintaining proteostasis in the human disease cystic fibrosis. Mol Biol Cell 21:871-884. https://doi.org/10.1091/mbc.E09-12-1017

60. Lasagna-Reeves CA, Castillo-Carranza DL, Sengupta U, Sarmiento J, Troncoso J, Jackson GR, Kayed R (2012) Identification of oligomers at early stages of tau aggregation in Alzheimer's disease. FASEB J 26:1946-1959. https://doi.org/10.1096/f.1 1-199851

61. Laurent C, Buee L, Blum D (2018) Tau and neuroinflammation: what impact for Alzheimer's disease and tauopathies? Biomed J 41:21-33. https://doi.org/10.1016/j.bj.2018.01.003

62. Li J, Richter K, Reinstein J, Buchner J (2013) Integration of the accelerator Aha1 in the Hsp90 co-chaperone cycle. Nat Struct Mol Biol 20:326-331. https://doi.org/10.1038/nsmb.2502

63. Li J, Soroka J, Buchner J (2012) The Hsp90 chaperone machinery: conformational dynamics and regulation by co-chaperones. Biochim Biophys Acta 1823:624-635. https://doi.org/10.1016/j.bbamcr.2011.09. 003

64. Liddelow SA, Guttenplan KA, Clarke LE, Bennett FC, Bohlen CJ, Schirmer L, Bennett ML, Munch AE, Chung WS, Peterson TC et al (2017) Neurotoxic reactive astrocytes are induced by activated microglia. Nature 541:481-487. https://doi.org/10.1038/nature21029

65. Lindwall G, Cole RD (1984) Phosphorylation affects the ability of tau protein to promote microtubule assembly. J Biol Chem 259:5301-5305

66. Lorenz OR, Freiburger L, Rutz DA, Krause M, Zierer BK, Alvira S, Cuellar J, Valpuesta JM, Madl T, Sattler M et al (2014) Modulation of the Hsp90 chaperone cycle by a stringent client protein. Mol Cell 53:941-953. https://doi.org/10.1016/j.molcel.2014.02.003

67. Meimaridou E, Gooljar SB, Ramnarace N, Anthonypillai L, Clark AJ, Chapple JP (2011) The cytosolic chaperone Hsc70 promotes traffic to the cell surface of intracellular retained melanocortin-4 receptor mutants. Mol Endocrinol 25:1650-1660. https://doi.org/10.1210/me.2011-1020

68. Miyata Y, Koren J, Kiray J, Dickey CA, Gestwicki JE (2011) Molecular chaperones and regulation of tau quality control: strategies for drug discovery in tauopathies. Future Med Chem 3:1523-1537. https://doi. org/10.4155/fmc.11.88

69. Mouton PR, Pakkenberg B, Gundersen HJ, Price DL (1994) Absolute number and size of pigmented locus coeruleus neurons in young and aged individuals. J Chem Neuroanat 7:185-190. https://doi.org/10. 1016/0891-0618(94)90028-0

70. Mukaetova-Ladinska EB, Garcia-Siera F, Hurt J, Gertz HJ, Xuereb JH, Hills R, Brayne C, Huppert FA, Paykel ES, McGee M et al (2000) Staging of cytoskeletal and beta-amyloid changes in human isocortex reveals biphasic synaptic protein response during progression of Alzheimer's disease. AmJPathol 157:623-636

71. Narasimhan S, Guo JL, Changolkar L, Stieber A, McBride JD, Silva LV, He Z, Zhang B, Gathagan RJ, Trojanowski JQ et al (2017) Pathological tau strains from human brains recapitulate the diversity of tauopathies in nontransgenic mouse brain. J Neurosci 37:11406-11423. https://doi. org/10.1523/JNEUROSCl.1230-17.2017

72. Nelson PT, Alafuzoff I, Bigio EH, Bouras C, Braak H, Cairns NJ, Castellani RJ, Crain BJ, Davies P, Del Tredici Ket al (2012) Correlation of Alzheimer disease neuropathologic changes with cognitive status: a review of 
the literature. J Neuropathol Exp Neurol 71:362-381. https://doi.org/10. 1097/NEN.0b013e31825018f7

73. Oddo S, Caccamo A, Shepherd JD, Murphy MP, Golde TE, Kayed R, Metherate R, Mattson MP, Akbari Y, LaFerla FM (2003) Triple-transgenic model of Alzheimer's disease with plaques and tangles: intracellular Abeta and synaptic dysfunction. Neuron 39:409-421

74. Oroz J, Chang BJ, Wysoczanski P, Lee C-T, Pérez-Lara Á, Chakraborty P, Hofele RV, Baker JD, Blair LJ, Biernat J et al (2018) Structure and pro-toxic mechanism of the human Hsp90/PPlase/Tau complex. Nat Commun 9:4532. https://doi.org/10.1038/s41467-018-06880-0

75. Ratajczak T, Carrello A (1996) Cyclophilin 40 (CyP-40), mapping of its hsp90 binding domain and evidence that FKBP52 competes with CyP40 for hsp90 binding. J Biol Chem 271:2961-2965. https://doi.org/10. 1074/jbc.271.6.2961

76. Riggs DL, Roberts PJ, Chirillo SC, Cheung-Flynn J, Prapapanich V, Ratajczak T, Gaber R, Picard D, Smith DF (2003) The Hsp90-binding peptidylprolyl isomerase FKBP52 potentiates glucocorticoid signaling in vivo. EMBO J 22:1158-1167. https://doi.org/10.1093/emboj/cdg108

77. Roberson ED, Scearce-Levie K, Palop JJ, Yan F, Cheng IH, Wu T, Gerstein H, Yu GQ, Mucke L (2007) Reducing endogenous tau ameliorates amyloid beta-induced deficits in an Alzheimer's disease mouse model. Science 316:750-754

78. Robinson JL, Geser F, Corrada MM, Berlau DJ, Arnold SE, Lee VM, Kawas $\mathrm{CH}$, Trojanowski JQ (2011) Neocortical and hippocampal amyloid-beta and tau measures associate with dementia in the oldest-old. Brain 134:3708-3715. https://doi.org/10.1093/brain/awr308

79. Sabbagh MN, Cooper K, DeLange J, Stoehr JD, Thind K, Lahti T, Reisberg B, Sue L, Vedders L, Fleming SR et al (2010) Functional, global and cognitive decline correlates to accumulation of Alzheimer's pathology in $\mathrm{MCl}$ and AD. Curr Alzheimer Res 7:280-286

80. Sahasrabudhe P, Rohrberg J, Biebl MM, Rutz DA, Buchner J (2017) The Plasticity of the Hsp90 Co-chaperone system. Mol Cell 67(947961):e945. https://doi.org/10.1016/j.molcel.2017.08.004

81. Saito T, Mihira N, Matsuba Y, Sasaguri H, Hashimoto S, Narasimhan S, Zhang B, Murayama S, Higuchi M, LeeVMY et al (2019) Humanization of the entire murine Mapt gene provides a murine model of pathological human tau propagation. J Biol Chem 294:12754-12765. https://doi.org/10.1074/jbc. RA119.009487

82. Santacruz K, Lewis J, Spires T, Paulson J, Kotilinek L, Ingelsson M, Guimaraes A, DeTure M, Ramsden M, McGowan E et al (2005) Tau suppression in a neurodegenerative mouse model improves memory function. Science (New York, NY) 309:476-481. https://doi.org/10.1126/science. 1113694

83. Saraiva J, Nobre RJ, Pereira de Almeida L (2016) Gene therapy for the CNS using AAVs: The impact of systemic delivery by AAV9. J Control Release 241:94-109. https://doi.org/10.1016/j.jconrel.2016.09.011

84. Sasaki A, Kawarabayashi T, Murakami T, Matsubara E, Ikeda M, Hagiwara H, Westaway D, George-Hyslop PS, Shoji M, Nakazato Y (2008) Microglial activation in brain lesions with tau deposits: comparison of human tauopathies and tau transgenic mice TgTauP301L. Brain Res 1214:159168. https://doi.org/10.1016/j.brainres.2008.02.084

85. Schmidt C, Beilsten-Edmands V, Robinson CV (2015) The joining of the $\mathrm{Hsp90}$ and $\mathrm{Hsp} 70$ chaperone cycles yields transient interactions and stable intermediates: insights from mass spectrometry. Oncotarget 6:18276-18281. https://doi.org/10.18632/oncotarget.4954

86. Schmidt ML, Huang R, Martin JA, Henley J, Mawal-Dewan M, Hurtig HI, Lee VM, Trojanowski JQ (1996) Neurofibrillary tangles in progressive supranuclear palsy contain the same tau epitopes identified in Alzheimer's disease PHFtau. J Neuropathol Exp Neurol 55:534-539

87. Scholl M, Lockhart SN, Schonhaut DR, O'Neil JP, Janabi M, Ossenkoppele R, Baker SL, Vogel JW, Faria J, Schwimmer HD et al (2016) PET imaging of tau deposition in the aging human brain. Neuron 89:971-982. https:// doi.org/10.1016/j.neuron.2016.01.028

88. Seibenhener ML, Wooten MC (2015) Use of the open field maze to measure locomotor and anxiety-like behavior in mice. J Vis Exp 96:e52434. https://doi.org/10.3791/52434

89. Serrano-Pozo A, Frosch MP, Masliah E, Hyman BT (2011) Neuropathological alterations in Alzheimer disease. Cold Spring Harb Perspect Med 1:a006189. https://doi.org/10.1101/cshperspect.a006189

90. Shelton LB, Baker JD, Zheng D, Sullivan LE, Solanki PK, Webster JM, Sun Z, Sabbagh JJ, Nordhues BA, Koren J 3rd et al (2017) Hsp90 activator
Aha1 drives production of pathological tau aggregates. Proc Natl Acad Sci USA 114:9707-9712. https://doi.org/10.1073/pnas.1707039114

91. Shelton LB, Koren J 3rd, Blair LJ (2017) Imbalances in the Hsp90 chaperone machinery: implications for tauopathies. Front Neurosci 11:724. https://doi.org/10.3389/fnins.2017.00724

92. Sivils JC, Storer CL, Galigniana MD, Cox MB (2011) Regulation of steroid hormone receptor function by the 52-kDa FK506-binding protein (FKBP52). Curr Opin Pharmacol 11:314-319. https://doi.org/10.1016/j. coph.2011.03.010

93. Spillantini MG, Goedert M (2013) Tau pathology and neurodegeneration. Lancet Neurol 12:609-622. https://doi.org/10.1016/S14744422(13)70090-5

94. Sticozzi C, Belmonte G, Meini A, Carbotti P, Grasso G, Palmi M (2013) IL-1 beta induces GFAP expression in vitro and in vivo and protects neurons from traumatic injury-associated apoptosis in rat brain striatum via NFkappaB/Ca(2)(+)-calmodulin/ERK mitogen-activated protein kinase signaling pathway. Neuroscience 252:367-383. https://doi.org/10. 1016/j.neuroscience.2013.07.061

95. Stiegler SC, Rubbelke M, Korotkov VS, Weiwad M, John C, Fischer G, Sieber SA, Sattler M, Buchner J (2017) A chemical compound inhibiting the Aha1-Hsp90 chaperone complex. J Biol Chem 292:17073-17083. https://doi.org/10.1074/jbc.M117.797829

96. Sun L, Prince T, Manjarrez JR, Scroggins BT, Matts RL (2012) Characterization of the interaction of Aha1 with components of the Hsp90 chaperone machine and client proteins. Biochim Biophys Acta 1823:1092-1101. https://doi.org/10.1016/j.bbamcr.2012.03.014

97. Tatro ET, Everall IP, Kaul M, Achim CL (2009) Modulation of glucocorticoid receptor nuclear translocation in neurons by immunophilins FKBP51 and FKBP52: implications for major depressive disorder. Brain Res 1286:1-12. https://doi.org/10.1016/j.brainres.2009.06.036

98. Tatsumi S, Uchihara T, Aiba I, Iwasaki Y, Mimuro M, Takahashi R, Yoshida M (2014) Ultrastructural differences in pretangles between Alzheimer disease and corticobasal degeneration revealed by comparative light and electron microscopy. Acta Neuropathol Commun 2:161. https:// doi.org/10.1186/s40478-014-0161-3

99. Uchihara T (2014) Pretangles and neurofibrillary changes: similarities and differences between $A D$ and $C B D$ based on molecular and morphological evolution. Neuropathology 34:571-577. https://doi.org/10. 1111/neup.12108

100. Wang X, Venable J, LaPointe P, Hutt DM, Koulov AV, Coppinger J, Gurkan C, Kellner W, Matteson J, Plutner H et al (2006) Hsp90 cochaperone Aha1 downregulation rescues misfolding of CFTR in cystic fibrosis. Cell 127:803-815. https://doi.org/10.1016/j.cell.2006.09.043

101. Weickert S, Wawrzyniuk M, John LH, Rudiger SGD, Drescher M (2020) The mechanism of Hsp90-induced oligomerizaton of Tau. Sci Adv 6:eaax6999. https://doi.org/10.1126/sciadv.aax6999

102. Wingo AP, Dammer EB, Breen MS, Logsdon BA, Duong DM, Troncosco JC, Thambisetty M, Beach TG, Serrano GE, Reiman EM et al (2019) Largescale proteomic analysis of human brain identifies proteins associated with cognitive trajectory in advanced age. Nat Commun 10:1619. https://doi.org/10.1038/s41467-019-09613-z

103. Wochnik GM, Rüegg J, Abel GA, Schmidt U, Holsboer F, Rein T (2005) FK506-binding proteins 51 and 52 differentially regulate dynein interaction and nuclear translocation of the glucocorticoid receptor in mammalian cells. J Biol Chem 280:4609-4616. https://doi.org/10.1074/ jbc.M407498200

104. Yoshiyama Y, Higuchi M, Zhang B, Huang SM, Iwata N, Saido TC, Maeda J, Suhara T, Trojanowski JQ, Lee VM (2007) Synapse loss and microglial activation precede tangles in a P301S tauopathy mouse model. Neuron 53:337-351. https://doi.org/10.1016/j.neuron.2007.01.010

\section{Publisher's Note}

Springer Nature remains neutral with regard to jurisdictional claims in published maps and institutional affiliations. 